\title{
A review on methods to estimate a CT from MRI data in the context of MRI-alone RT
}

\author{
Type of article: Review \\ Wafa Boukellouz ${ }^{1}$ and Abdelouahab Moussaoui \\ Department of informatics, Faculty of sciences, Ferhat Abbas University, Setif, Algeria.
}

\begin{abstract}
Background: In recent years, Radiation Therapy (RT) has undergone many developments and provided progress in the field of cancer treatment. However, dose optimisation each treatment session puts the patient at risk of successive X-Ray exposure from Computed Tomography CT scans since this imaging modality is the reference for dose planning. Add to this difficulties related to contour propagation. Thus, approaches are focusing on the use of MRI as the only modality in RT. In this paper, we review methods for creating pseudo-CT images from MRI data for MRI-alone RT. Each class of methods is explained and underlying works are presented in detail with performance results. We discuss the advantages and limitations of each class.

Methods: We classified recent works in deriving a pseudo-CT from MR images into four classes: segmentation-based, intensity-based, atlas-based and hybrid methods and the classification was based on considering the general technique applied.

Results: Most research focused on the brain and the pelvic regions. The mean absolute error ranged from 80 to $137 \mathrm{HU}$ and from 36.4 to $74 \mathrm{HU}$ for the brain and pelvis, respectively. In addition, an interest in the Dixon MR sequence is increasing since it has the advantage of producing multiple contrast images with a single acquisition.

Conclusion: Radiation therapy is emerging towards the generalisation of MRI-only RT thanks to the advances in techniques for generation of pseudo-CT images and the development of specialised MR sequences favouring bone visualisation. However, a benchmark needs to be established to set in common performance metrics to assess the quality of the generated pseudo-CT and judge on the efficiency of a certain method.
\end{abstract}

Keywords:MRI-alone RTP, Pseudo-CT, Electron density, Radiotherapy treatment planning.

Corresponding author: Ms Wafa Boukellouz Department of informatics, Faculty of sciences, Ferhat Abbas University, Setif, Algeria. Email: w_boukellouz@outlook.fr

Received: September 05, 2017, Accepted: October 30, 2017, English editing: January 14, 2018, Published: March 19, 2018.

Screened by iThenticate.@2018KNOWLEDGE KINGDOM PUBLISHING.

\section{Introduction}

Radiation Therapy (RT) is a treatment that consists of delivering high doses of ionising radiation to a tumourin order to destroy it. This treatment option has undergone many developments starting from whole body radiation therapy to conformal radiotherapy; this latter allows to deliver a limited number of high doses to cancerous cells devised on small fractions while keeping the dose delivered to the surrounding organs minimal. One important step in the process of Radiation Treatment Planning (RTP) is imaging, where a series of imaging studies, usually CT, MRI and PET scans are performed. Among these, Computed Tomography (CT) is used as the primary imaging modality, as the dose planning relies on the electron density information from CT scans (see Figure 1 for an example of 4D dose distribution resulting from a carbon ion spot beam, computed on a 4D CT volume). However, accurate delineation of a tumour and other organs on CT scans is difficult because of its poor soft tissue contrast. In the case of prostate and rectum cancers, studies have shown that the prostate and rectum volumes are overestimated when contoured on CT scans compared to the delineated volumes on MR images $(1,2)$. 


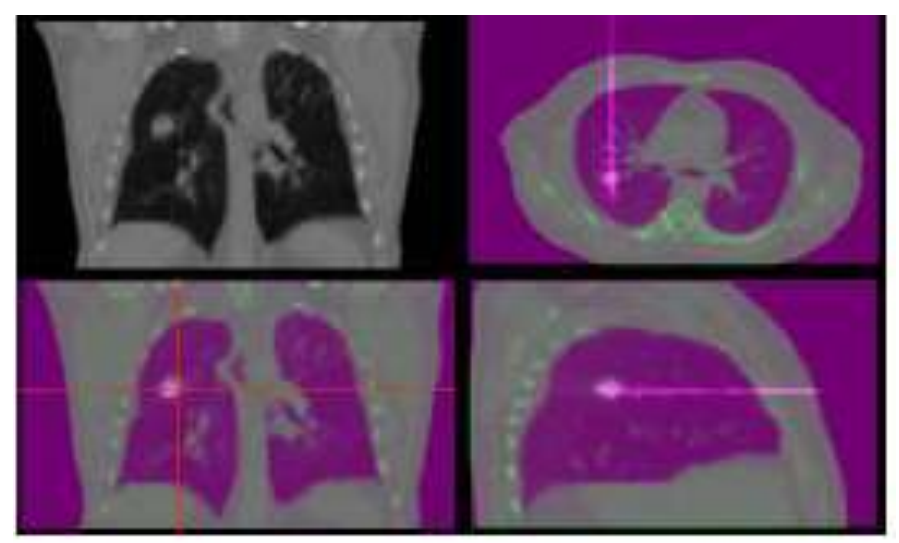

Figure $.14 \mathrm{D}$ dose distribution resulting from a carbon ion spot beam computed on a 4D CT image.

Hence, Magnetic Resonance Imaging (MRI) is used jointly with CT for its excellent soft tissue contrasts that are based on multiple contrast parameters (3). MRI is characterised by its superior soft tissue contrasts that allow distinguishing several tissues and organs (see Figure 2). It is based on physical characteristics of Nuclear Magnetic Resonance (NMR) of water protons in the body. Radio waves are used to excite the nuclei of hydrogen atoms within the patient's body. These radio waves are subsequently re-emitted by the patient in a manner, which is characteristic of the NMR properties of the tissues involved, detected, digitised and processed by a computer and displayed as tomographic slices revealing the distribution of different tissues.

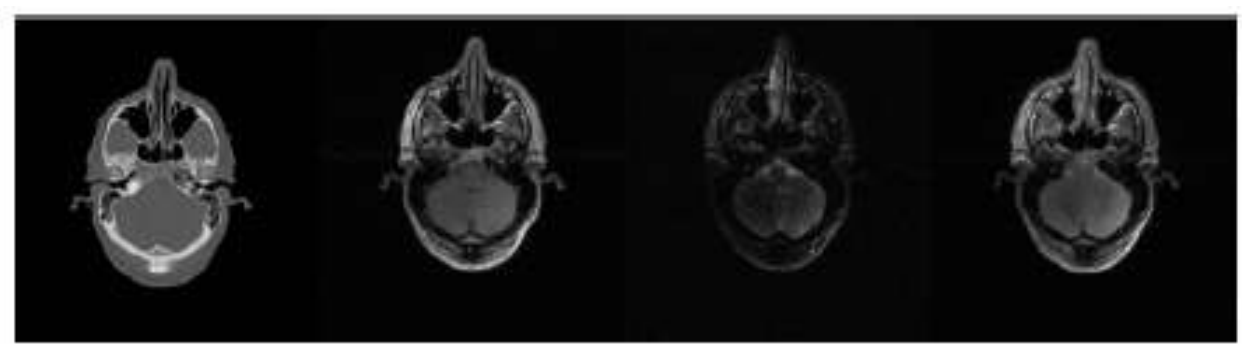

Figure .2 Brain CT, T1-weighted, T2-weighted and proton density MRI slices (from left to right) showing the different contrasts provided by MRI compared to CT.

Thus, MRI is used for defining the target volume and Organs At Risk (OAR). Afterwards, these contours are transferred to CT data using contour propagation techniques (4-8) for dose calculations; contour propagation is achieved by spatially aligning the $\mathrm{CT}$ and MR images using image registration techniques (9). However, this task can result in a mean registration error of approximatively $2 \mathrm{~mm}$ in body organs such as the prostate, which can cause a significant shift in target volume definition, consequently leading to a reduction in treatment accuracy and efficiency (10-12).

Nowadays, studies strive for using MRI as the only modality in radiation therapy to take advantage of its soft tissue high contrast, remove registration uncertainties, reduce financial cost and imaging time and limit radiation exposure from X-Ray scans. Moreover, with the increasing development of MRI, this imaging modality has become the tool of choice for many treatments. Therefore, 
the need for a strategy that can combine the dose planning and an excellent structures visualisation has called for an MRI-alone RTP; the idea is to derive a CT or a so-called pseudo-CT from MRI data. Nevertheless, MRI cannot be used directly for dose planning because MR intensities correlate with proton densities and relaxation properties, whereas dose calculations require data on Electron Density (ED) derived from CT scans. Therefore, ED information needs to be assigned to MR images.

The earliest approaches for assigning ED information to MR images consisted of setting the whole body to a uniform bulk density value (usually corresponding to water) and assigned a different bulk density for bone volume (13-16) Beavis et al. (13) used a water method for an MRI-alone radiation therapy workflow. The whole body was set to a homogeneous electron density value of water. Despite its simplicity, this approach cannot generate a reliable CT reference for dose calculation and may lead to erroneous results (17).

An improved approach that segments the anatomy into different tissue classes and assigns a uniform bulk density values for each class $(14,18,19,15,16,20)$. In (14), contoured CT images were used to derive electron density information using two approaches: one consists in setting the whole body to a homogenous CT value of water $(0 \mathrm{HU})$, and the other approach created a bone + water image were bone was manually contoured on CT scans, these contours were assigned an average Hounsfield Unit (HU) value of four patients $(320 \mathrm{HU})$. The rest of the voxels were assigned the value of $0 \mathrm{HU}$. The bone + water approach was applied to segmented MR images and assigned the corresponding derived HU values to each segment. Chen et al. (18) delineated the bony structures of the pelvic (femoral heads and scrum) manually on T2-weighted sequences and assigned to them a bulk value of $2.0 \mathrm{~g} / \mathrm{cm} 3 \mathrm{in}$ order to perform an MRI-based Intensity-Modulated Radiation Therapy (IMRT). Dose differences between the CT-based and their MRI-based dose plans were within the accepted clinical criteria $(2 \%)$.

In (19), Eilertsenet al. investigated the dosimetric accuracy of treatment plans created from pseudo-CT images estimated using three approaches; the first approach is water-based where the whole volume was set to the value of $1.02 \mathrm{~g} /$ $\mathrm{cm} 3$. The second approach assigned the value of $1.3 \mathrm{~g} / \mathrm{cm} 3$ for the segmented pelvic bone and the rest of the body was assigned the value of $1.02 \mathrm{~g} / \mathrm{cm} 3$. The last approach is similar to the second one, only differed by assigning the bone a value of $2.1 \mathrm{~g} / \mathrm{cm} 3$. Results for dose distribution differences for IMRT plans revealed that the second approach (with bone assigned a bulk value of $1.3 \mathrm{~g} / \mathrm{cm} 3$ ) performed better with the relative difference of the mean dose to the Clinical Target Volume (CTV) equal to $-1.6 \% \pm 0.4$, compared to $-2.8 \% \pm 0.5$ and $-4.3 \% \pm 1.7$ for the water and the " $2.1 \mathrm{~g} / \mathrm{cm} 3$ "-bone approaches, respectively. Furthermore, authors mentioned that the dose inhomogeneity in the CTV increases when bone is set to the value of $2.1 \mathrm{~g} / \mathrm{cm} 3$.

Lambert et al. (16) assigned the bulk value of $1.13 \mathrm{~g} / \mathrm{cm} 3$ for the pelvic bone in MR images to investigate on the dosimetric accuracy of the generated plans compared to the full density CT-based (Gold standard) and water-based plans. Results showed an average dose difference of $1.3 \%$ between the gold standard and the MRI-based bone bulk density plan compared to $2.5 \%$ of dose differences between the MRI-based bone bulk density plan and the water approach. Hoogcarspel et al. (21) investigated the dosimetric accuracy of different bulk density approaches forcreating a pseudo-CT from MRI data in the context of Stereotactic Body Radiation Therapy (SBRT) for spine metastases. Five different 
pseudo-CT images were generated based on different tissue segmentations (water density, lung density, bone density, fat density and heterogeneous density). The heterogeneous density pseudo-CT was generated by aligning fat and water Dixonbased MR sequences to a CT containing contours for the target volume. This was done to assign the electron density value of the target volume to the MR image. Therefore, creating a pseudo-CT containing the electron density values of fat, water, lung and bone. The Gamma pass rate was set to $\geq 95 \%$ as the success rate to quantify the dosimetric accuracy of the investigated approaches. The first four approaches presented unacceptable results going from $78 \%$ and bellow, whereas the heterogeneous density approach performed better with $99 \%$ pass rate. Furthermore, dose differences within the target volume showed better results for the latter approach compared to water and fat approaches, i.e., $0.13 \%$ compared to $-2.66 \%$ and $2.46 \%$, respectively. Authors stated that when using additional bulk densities, the dosimetric accuracy improves. However, this approach cannot be considered fully based on MRI alone for the reason that it depends on CT images to assign the electron density of spinal bone. Karotki et al. (22) assigned three bulk densities to the segmented bone, air cavities and air $(1.5 \mathrm{~g} / \mathrm{cm} 3,0 \mathrm{~g} / \mathrm{cm} 3$, and $1 \mathrm{~g} / \mathrm{cm} 3$, respectively). Nevertheless, these approaches suffer from segmentation errors and the required time for segmentation is significantly extended.

Aside from the above-mentioned methods, more sophisticated approaches are developed in order to assign the ED information to MRI data which is the interest of this paper. We review and classify methods for generating pseudo-CT images from MRI data. A classification of these methods with a detailed description of research works involved in each class of methods and some statistical performance results are presented. Nonetheless, one cannot make a direct comparison between these approaches in the absence of a generalised benchmark because of differences in the considered body region, datasets, MRI sequence parameters, applied RT and types of performance metrics used to evaluate the approach. We further address the advantages and drawbacks of each class of methods and discuss new orientations to deal with the limitation and difficulties encountered.

\section{Performance metrics}

To evaluate the performance of a certain method for creating a pseudo-CT from MRI, the generated pseudo-CT is compared to the gold standard CT (generally a real CT) using different performance measures. We grouped evaluation measures to geometric and dosimetric measures. The current section presents the common metrics used for evaluation.

\subsection{Geometric evaluation measures}

Measures in this category evaluate the voxel-wise differences between the original and pseudo-CT in HU values. We find the Mean Absolute Error (MAE) and the Mean Error (ME). Their respective equations are given by:

$$
M A E=\frac{1}{N} \sum_{i=1}^{N} \mid C T_{i}-\text { pseudoCT } i,
$$

and

$$
M E=\frac{1}{N} \sum_{i=1}^{N} C T_{i}-p s e u d o C T_{i},
$$

Where $\mathrm{N}$ is the number of voxels, $C T_{i}$ andpseudoCT $T_{i}$ are the $\mathrm{HU}$ value of a voxel at index $i$ in the gold standard CT and the pseudo-CT, respectively. 
The Dice Similarity Coefficient (DSC) for bone (24) is a metric that measures the overlap between the original CT and the pseudo-CT bone volumes. It is given by the following formula:

$$
D S C_{\text {bone }}=\frac{2\left(V_{C T} \cap V_{\text {pseudo }}-C r\right)}{V_{C T}+V_{\text {pseudo }}-C T},
$$

Where $V$ is the bone volume in the original CT and pseudo-CT.

\subsection{Dosimetric evaluation measures}

Metrics in this category evaluate the dose differences of the generated plans between the original CT and the pseudo-CT. One common metric is the gamma index $\gamma(25)$ that evaluates the dose distribution differences between each voxel in the original CT and the pseudo-CT.

$$
r=\min \left(\sqrt{\frac{\Delta r^{2}}{\Delta r_{\max }^{2}}+\frac{\Delta D^{2}}{\Delta D_{\max }^{2}}}\right) .
$$

Where ${ }^{\Delta t}$ and ${ }_{\text {.... }}^{\Delta L}$ are respectively distance and dose between a voxel of interest and a neighbouring voxel in two dose distributions. ${ }^{\Delta r_{\max }{ }^{i}}$ and ${ }^{\perp D_{\max }}$ are the defined success thresholds. Generally, they are set to these values ${ }^{\Delta r_{\max }=2 \mathrm{~mm}}$ : and $\Delta D_{\max }=2 \%$ of the prescribed dose.

The Dose Volume Histogram (DVH) compares dose distributions, which expresses the minimal dose $\left(\mathrm{D}_{V}\right)$ that a volume $V$ (expressed in percent) receives. For example, $\mathrm{D}_{98}$ is the minimal dose delivered to $98 \%$ of the volume of interest. Probably add other measures without explanation

\section{Classification of pseudo-CT generation methods}

The existing work in deriving a pseudo-CT from MR images can be broadly classified into four categories: segmentation-based, intensity-based, atlas-based and hybrid methods. This latter consists of approaches combining methods of the earlier categories. The choice of this classification scheme was based on considering the general technique applied in the approach. Other classifications exist, where three categories are established, each grouping segmentation-based, atlas-based and hybrid approaches (26). We preferred to make a broad categorizationin order to give a more understanding of the methods. Figure 3 presents a diagram describing the classification with some underlying techniques. This section provides a detailed overview of each class with related works classified chronologically. In this paper, the term pseudo-CT is used to refer to the MR image assigned ED information. 


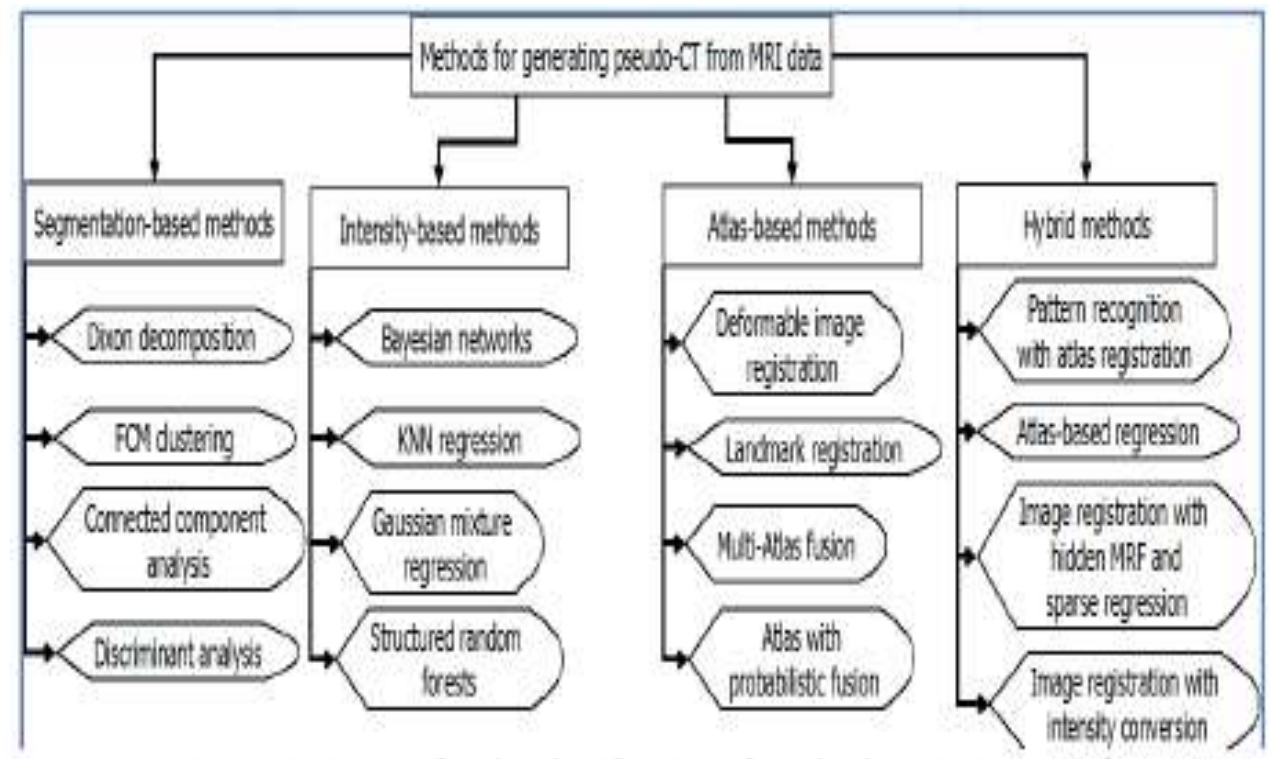

Figure .3 Diagram for the classification of methods assigning ED information to MR images with some underlying techniques.

\subsection{Segmentation-based approaches}

These approaches rely on segmenting MR images into several tissue classes: usually three, 4 or 5 classes, for example, bone, air, soft tissue and fat, based on Dixon sequences (27-30), or using fuzzy logic algorithms $(31,32,27,33,34)$. Then, each tissue class is assigned a specific HU value in order to obtain the final pseudoCT.

Zaidi et al. (31) presented an MR segmentation approach for attenuation and scatter correction in a 3D Positron Emission Tomography (PET) by generating a patient-specific attenuation map. After extraction of the skull and scalp on T1weighted MR images, they were registered to their corresponding reconstructed 3D PET images, followed by recording spatial information from the registered maps. This information was applied to the original MR images that were segmented using a fuzzy C-means algorithm to yield four tissue classes. Each class was assigned attenuation coefficients to obtain the final MR segmented attenuation map. Qualitative and quantitative results show an improvement compared to the clinical 3D brain PET reconstruction using attenuation and scatter correction guided by measured transmission. However, this approach follows many processing steps, which may introduce a long processing time. Moreover, the accuracy of the MRPET registration depends on the used method and may introduce some registration errors. In addition, the intensity inhomogeneity artifacts present in the MR images introduced a shading effect after the segmentation process. This latter needed some manual interventions from the operator.

In (35), Boettger et al. used two sets of MR images namely: UTE sequence to enhance visualisation of bony structures and an enhanced contrast sequence for soft tissue visualisation. The first data set of MR images comprised of two sequences, one with an Ultrashort Echo Time pulse (UTE1) and the other with a longer TE pulse (UTE2). The second sequence (UTE2) was auto-segmented for skin detection; pixel intensity values of this sequence were subtracted from the first sequence (UTE1) to improve bone visualisation. Moreover, They generated 
Digitally Reconstructed Radiographs (DDRs) based on a look-up table that maps MR intensities to electron density values using predefined thresholds. Furthermore, a pseudo-CT was generated by assigning $\mathrm{HU}$ values to each tissue class (air, bone and soft tissue). The limitation of this approach is that the bone segmentation technique can be used only on UTE sequences. Moreover, this technique showed undesired results of over-segmenting and under-segmenting partial regions of the brain.

Berker et al. (27) presented a four-class tissue segmentation approach for MRIbased attenuation correction. The MR images used are a UTE triple echo sequences where the cortical bone segmentation is achieved by using a dual echo technique (36). Soft tissue and adipose tissues were segmented using a Dixon decomposition $(28,29)$, then the attenuation coefficients are assigned to each tissue class. The approach presented a misclassification between bone and soft tissue voxels.

In (32), authors presented a classification approach to generate a pseudo-CT from several MR images such as T1-weighted, T2-weighted, and two echoes from an Ultra-short Echo Time (UTE) sequence. Next, fat and water images were calculated using a Dixon method. These images were used to distinguish the major tissue types of bone, fat, solid tissue, fluid and air. The MR images were aligned together and then a fuzzy c-means classification was performed in order to identify regions of interest and classify tissues. Each tissue class was assigned a fuzzy membership probability and an appropriate attenuation property. The final pseudo$\mathrm{CT}$ is generated by summing attenuation properties of each voxel. However, results show that the classifier tended to misclassify air as bone and the use of UTE sequences does not completely separate bone from the air.

In (37), Rank et al. presented a classification approach using discriminant analysis to derive a pseudo-CT from different MR contrasts. The MR images were resampled to $\mathrm{CT}$ resolution with linear interpolation and then, each MR image was co-registered to its corresponding $\mathrm{CT}$ with rigid registration taking mutual information as a similarity measure. A threshold mask was used to limit the area of interest and cross-validation was performed for parameter optimisation. The optimisation resulted in TSE1 and UTE1 sequences as the best MR contrast combination with two features used (box.sd: the standard deviation of the surrounding box including the central voxel multiplied by the intensity of the voxel and dist.center: the absolute distance of the voxel to the centre of the 2D slice).Discriminant analysis is employed to assign observation variable vectors composed of MR intensities features of a given voxel to predefined classes using decision rules obtained in the learning step. Each CT class is a $35 \mathrm{HU}$ rang in the CT scale. Results showed a MAE of $81 \mathrm{HU}, 95.2 \mathrm{HU}$ and $90.1 \mathrm{HU}$ for each phantom used, respectively. The standard deviations of the absolute error between voxels were in the range of 130 to $152 \mathrm{HU}$, which is a significantly large interval. For Ion Radiotherapy Treatment (IRT) plan simulation, mean doses of the Planning Target Volume (PTV) were 1.4-3.1\% higher and volumes with PTV doses less than $90 \%$ of the prescribed doses were $2.2-8.3 \%$ smaller compared to the original CT based dose planning calculations.

Navalpakkam et al. (38) used UTE and 3D Dixon-VIBE sequences to predict pseudo-CT images to be used for the generation of $\mu$-maps for MRI-based brain attenuation correction. The process starts by performing a voxel-wise addition of UTE-TE1 (used for bone identification), 3D-Dixon VIBE in-phase and 3D-Dixon VIBE out-phase images. The resulting image was used to identify air regions by applying the k-means clustering algorithm. To learn the relations between these 
processed images and their corresponding CT images. Five patients were integrated into the learning phase and support vector regression was used. Next, the generated regression model was applied to five new MR patients to predict their pseudo-CT images. Their approach gave a MAE of $2.4 \%$ with a Standard Deviation (SD) of $3.68 \%$ in PET quantification for the whole brain.

Su et al. (30) proposed a method for acquisition, correction and generation of a pseudo-CT image based on a single acquisition under-sampled UTE-m Dixon pulse sequence. Two point Dixon volumes were reconstructed to provide water and fat images. These images were used along aside with $\mathrm{R}^{*}$ images, which provide bone information as inputs for an unsupervised clustering algorithm to estimate five tissue classes namely: air, brain, fat, fluid and bone, each class was assigned a specific $\mathrm{HU}$ value to yield the final pseudo-CT. The mean absolute prediction deviation between the gold standard (low dose CT) and the pseudo-CT was 130 \pm 16 $\mathrm{HU}$ and the mean prediction deviation was $-22 \pm 29 \mathrm{HU}$.

Khateri et al. (33) used short-TE and two-point Dixon MR sequences to generate $\mu$-maps using Fuzzy C-means (FCM) algorithm focusing on bone identification. Fat and water masks were derived from the in-phase, water, and fat images using a modified C-means algorithm. The soft tissue mask was the result of summing the air and water masks, this mask was applied to the short-TE sequence. Later, this image was segmented based on a fuzzy C-means algorithm yielding four tissue classes: bone, air, adipose tissue and soft tissue; each of these classes belonging to a particular HU interval was assigned attenuation values.

Liu et al. (39) employed T1 Dixon MR sequences in a classification scheme combined with shape analysis to create a pseudo-CT. First, an initial mask was generated by combining T1, water and fat images to detect bone and air voxels. Then, a bone shape model (40) was applied to this mask in order to identify the pelvic bone. Femur bone was detected using 3D connected component analysis. To segment the rest of the body, a modified version of the FCM algorithm was applied and five tissue classes were identified including compact bone, fat, muscle, and the combination of fat interfaces and bone marrow. The pseudo-CT was generated by assigning a specific $\mathrm{HU}$ value for each tissue class. MAE \pm SD was $274.9 \pm 26.9 \mathrm{HU}$ for solid bone averaged on nine patients while muscle had an error of $13.7 \pm 1.8 \mathrm{HU}$.

Bredfeldt et al. (41) generated pseudo-CT images for the liver using T1 Dixon MR sequences with FCM algorithm. The approach starts by performing intensity thresholding on T1, water and fat images yielding an air mask. In addition, the contours of the vertebral bone were segmented from the fat images using a learning approach $(42,43)$. T1, water, and segmented fat images were used as the input for a modified FCM algorithm (32) that resulted in different tissue classes depending on their intensity (mid-intensity, lower intensity, bone or marrow in the abdomen). The MAE ranged from 0 to $160 \mathrm{HU}$. However, the bone outside the segmented anterior vertebra bodies was misclassified as mid and lower intensity tissue. Nevertheless, this misclassification does not seem to affect the dose calculation very much where the absolute dose differences are within acceptable ranges (Median \pm 0.17 Gray (Gy) and Max $\pm 0.81 \mathrm{~Gy}$ ).

\subsection{Intensity-based approaches}

Intensity-based approaches assume a one-to-one correspondence between MR and CT voxels and characterize their intensities into tissue classes that are assigned 
electron density values (44-46). Additionally, machine learning algorithms are used to characterize the relations between $\mathrm{CT}$ and MRI voxels $(47,48)$.

Johansson et al. $(49,50)$ used three MR sequences, namely: T2-weighted 3D Spin Echo (SE) based sequence and two Ultra-short Echo Time (UTE) sequences (The UTE sequences are used to enhance visualization of bone). Their approach used a Gaussian mixture regression model to link the MR and CT intensities by performing clustering on the whole dataset with voxels from all tissues wherean intensity value characterizes each cluster. The pseudo-CT voxel values are calculated based on the estimated regression model. Streak artefacts in MR images caused the major differences between the original CT and the pseudo-CT. Furthermore, despite the use of UTE sequences to differentiate air and bone, their suggested approach had large deviations between the real CT and the pseudo-CT that were located at the air-soft tissue and bone-soft tissue interfaces. To address this problem, authors extended their work (51) by incorporation of spatial information, namely: $x, y$ and $z$ coordinates of each voxel and the shortest distance from each voxel to the external contour of the anatomy. Results show an improvement in complicated small structures, but no improvement was found in the larger anatomical volumes.

In (52), Kapanen et al used a T1/T2*-weighted 3D Gradient Echo (GE) MR sequence for pelvic bones. The relations between MR intensities and HU values were expressed using a polynomial model that is based on MR signal intensity and fitting parameters. The voxels of the segmented bone structures were grouped into sixteen subgroups based on their MR intensity values. The polynomial model was then applied to each of these subgroups to convert the mean MR intensities to Hounsfield values.

Kim et al. (53) presented a voxel-based weighted summation approach for generating a pseudo-CT from four MR sequences (3D T1-weighted Fast Field Echo (FFE) sequence, 3D T2-weighted Turbo Spin Echo (TSE) sequence, 3D balanced Turbo Field Echo sequence (bTFE) and an inverse intensity volumetric image) for prostate cancer patients. Authors manually contoured bone on T2-weighted sequences and registered them to their corresponding CT volumes using rigid registration. Each MR voxel intensity was calculated using a weighted summation of the intensities of the corresponding voxels of the four MR sequences. Weight optimization was performed to reduce errors starting with random weights to generate an initial pseudo-CT and optimizing by reducing the Euclidian distance of calculated voxel value differences between the pseudo-CT and real CT over one thousand iterations. In addition, the resulting optimized weights were used for the next pseudo-CT generation. Average MAE was $74.3 \pm 10.9 \mathrm{HU}$ for nine subjects; errors were located around bone contour borders. However, manual bone contouring may introduce uncertainty and it is time-consuming.

Korhonen et al. (54) presented a dual HU conversion model for deriving a pseudo-CT from MR sequences based on two conversion models. The first model was used to convert soft tissue MR signals to HU values: the idea is to mark Regions Of Interest (ROIs) on CT scans (100 ROI for each patient) covering muscle, urine, fat, prostate and rectal wall. These ROIs were then transferred to MR images via co-registration. The MR intensity scale was divided into ranges, each describing signals from different tissues (muscle, urine, fat, prostate and rectal wall) and each MR intensity value belonging to a specific signal rang is converted to the corresponding HU value. The second conversion model is for converting signals from the bone tissue; authors used the approach in (52) with a patient-specific cut- 
off to improve the representation of low-density signals because these can vary significantly between patients. Average tissue differences between the pseudo-CT and real CT ranged from -2 to $5 \mathrm{HU}$ for soft tissue, and from 22 to $78 \mathrm{HU}$ for bone. However, the conversion model overestimated $\mathrm{HU}$ values for low electron density structures, and the manual bone segmentation introduces a significant time. Moreover, the approach required manual adjustments of the signal cut-off for each patient, which is not practical.

Roy et al. (48) followed a Bayesian scheme to generate a pseudo-CT from two UTE MR sequences, each voxel of the reference images (two UTE sequences and one CT scan) and the subject data was represented by a feature vector called a patch. The subject and reference patches represent a local pattern of intensities that have been scaled to a similar intensity rang. Once the pairs of CT and MRI for both subject and reference are linked using a Gaussian distribution, the unknown CT patches for the subject are predicted and combined through the use of Bayesian networks.

In (55), Zhong et al. presented a new method that uses KNN regression with learned local descriptors to predict a CT from T1- and T2- weighted MR sequences. The approach consisted in extracting local compact descriptors for each region in the MR sequences; learning the transformations using the supervised descriptor technique (56) and predicting CT image using $\mathrm{KNN}$ regression; where, for each point $x$ of a subject MR image, a local search window centre is defined in the same location in the training CT-MR pairs. The prediction of the pseudo-CT was done by searching the K-nearest neighbours of each point descriptor in the test MR image, the result is $k \mathrm{MR}$ descriptors, by considering the alignment property of the MR-CT pairs, the $k$ samples of the corresponding CT are obtained. The final pseudo-CT is generated by performing a weighted average on the overlap CT patches. Another recent work by Huynh et al (57), where authors used structured random forests and auto context model to estimate a CT. Their method consists of partitioning each MR image into sets of patches where each patch is characterized by four features that are extracted at three levels (voxel level, sub-region level and whole patch level) including spatial information. To learn the relations between MR and CT patches, structured random forests are used to train the MR features. The resulting forests are used to predict initial CT patches. An auto-context model is employed to enhance the prediction of the CT. The previous CT patches are trained for new sets of random forests that are improved using ensemble model to yield the final CT predicted image.

\subsection{Atlas-based approaches}

The approaches in this class consist of using deformable registration algorithms (58-65) and a database of aligned CT-MR atlases. The MRI atlas is warped to a target MR image in order to capture the target's anatomy. Then the resulting registration transformations are applied to the $\mathrm{CT}$ atlas to predict the final pseudoCT image.

Kops et al. (66) followed a template-based scheme to create PET transmission images from MR sequences. Ten PET transmission scans were spatially normalized to the attenuation template of SPM2 (an SPM template is composed of a pair 
consisting of a PET transmission scan and its corresponding MR image), and averaged to create the transmission template. Each subject's MR and PET images were manually co-registered; then, the SMP2 MR template was spatially normalized to the co-registered MR image. The resulting transformation matrix is applied to the attenuation template to match the subject's anatomy.

Schreibmann et al. (67) used deformable image registration to create a pseudoCT from MR images. The idea is to warp an atlas CT image to the patient MR image combining a parametric and non-parametric registration algorithms namely BSpline and Hermosillo, respectively. B-Spline was used to account for large deformations while the Hermossilo algorithm was employed to refine the results from the B-Spline registration. To evaluate their results, authors used a threedimensional surface comparison tool to compare the differences between the pseudo-CT and the simulated CT (Gold standard). Test results show that $20 \%$ of surfaces have an error larger than $2 \mathrm{~mm}$ and less than $1 \%$ of the surfaces presented errors larger than $1 \mathrm{~cm}$ for the bone.

Greer and al. (68) presented an MRI-based workflow for radiation therapy, the subject's MR image was automatically segmented by registering it to an averaged set of manually segmented MR images used as an atlas. A matching CT atlas set was used for an automatic estimation of electron density values for each segment, therefore, mapping HU values to MR images.

Dowling et al. (69) presented an atlas-based electron density mapping method for auto-segmentation of MR images and pseudo-CT generation. To construct the atlas pair, a set of training MR-CT pairs was co-registered using rigid and affine registration. The atlas MR image is generated by iteratively registering training contoured MR images and averaging the results to obtain the atlas. The transformation metrics and deformation fields from the previous registration task are applied to the CT training set to generate the CT atlas. In order to estimate the pseudo-CT, the new patients MR image is registered to the atlas MR image for autosegmentation, then the same deformations are applied to the CT atlas.

In (17), authors used atlas registration between T1-weighted MR images and a template patient composed of matched pairs of CT-MR images to determine the geometry of each voxel (position) given its intensity in the T1 MR image. This information is represented by a Conditional Probability Function (PDF) and is combined into a unifying posterior PDF. This PDF is used to predict the unknown electron density values for the corresponding MR image.

Burgos et al. (70) proposed a multi-atlas scheme to synthetize a CT and attenuation maps. They used a set of atlas images composed of T1-weighted MR and CT scans. The first step aims at registering atlas images to the target MRI using symmetric global registration and B-spline parametrized non-rigid registration. Two morphological similarity measure were used: The Local Normalized Correlation Coefficient (LNCC) and the local Normalized Sum of Square Differences (NSSD). A ranking scheme was used to assign weights to the registered images, i.e., the better is the registration, and the higher is the weight. This step was followed by mapping the atlas CT scans to the transformation maps obtained in the previous step using the assigned weights to construct the target CT. However, the performance of this approach is limited by the anatomical information of CT scans and T1-weighted MR sequences and seems susceptible to the choice of optimization parameters.

Uh et al. (71) used atlas registration to create a pseudo-CT using T2-weighted Turbo Spin Echo (TSE) MR sequences based on multiple atlas images. The atlas 
set was composed of six pairs of MR-CT volumes that were registered with linear rigid-body registration. Atlas MR volumes were later registered to the patient MR volume using non-linear spatial registration. Then, the same deformations are applied to the atlas CT volumes. To generate the pseudo-CT, authors used three schemes to combine the deformed CTs, namely: arithmetic mean of each voxel in each of the deformed CTs (Mean6), pattern recognition with Gaussian process on 6 atlases, and on 12 atlases (PRGP6 and PRGP12). The intensity value of each voxel is a weighted average of the corresponding voxels of the deformed CTs. Results show that the generated pseudo-CT through PRGP12 performed better in terms of the Root Mean Square (RMS) difference compared to the real CT (207 HU compared to $219 \mathrm{HU}$ and $224 \mathrm{HU}$ for PRGP6 and Mean6, respectively). Concerning dose calculations, the $\mathrm{D}_{95}$ and the mean dose to the PTV results for the three schemes differed from the original values by $1.8 \%$ and $1.3 \%$ of the prescribed dose. The pseudo-CT generated with arithmetic mean showed the best value of the volume satisfying the Chi-evaluation (98.7 compared to 98.3 and 98.5 for PRGP6 and PRGP12, respectively). However, all three used schemes showed a smoothing effect where the high intensities in bone smear into the surrounding tissue. Moreover, the Gaussian process scheme is computationally expensive.

In (72), Sjölund et al proposedan atlas-based regression technique to derive a pseudo-CT from T1-weighted MR sequences. MRI and CT atlases were aligned with rigid registration. Then, the MR atlas volumes were warped to the target MR image using the deformable image registration algorithm Morphon (73) and a binary mask. The Morphon algorithm is based on estimating displacement vectors that point to the corresponding location in the target image. It uses local phase differences between signals of similar local frequency to estimate the spatial shift. This is done based on quadrature filters. The registration was performed on different scales to capture large global displacements and small local deformations. The resulting deformations were then applied to the atlas CT scans. The pseudo-CT was created by fusing the deformed atlases by iteratively registering the set to its joint mean.

Mérida et al. (74) presented a maximum probability approach to generate a pseudo-CT from T1-weighted MR sequences. Their maximum probability approach starts by registering atlas MRI to the target MRI volume. The transformations from this registration were warped to the atlas CT scans to deform them. For each voxel of these deformed CT volumes, a maximum probability class label was calculated considering three tissue classes (soft tissue, air, and bone) and the final voxel value is calculated by averaging $\mathrm{HU}$ values belonging to the maximum probability class of the corresponding voxels in all the deformed CT images.

In a more recent work, Arabi et al. (75) presented a two-step atlas method focusing on bone tissue identification. The first step aims at segmenting the target image in order to identify bone structures based on a voxel by voxel voting scheme; the result is a binary bone map. In the second step, a similarity measure is established between atlas CT images and the resulting bone map in order to define weights for the contribution of each CT atlas. An atlas fusion framework is locally optimized according to the resemblance to the obtained target bone map and the morphological similarity to the target MR volume.

Kraus et al. (76) used landmark image registration to predict a pseudo-CT based on a rigidly registered pair of MR and CT images. The Atlas MR image was registered to the target MRI using a marker-based rigid and deformable registration. 
This transformation is applied to the atlas CT to result in the pseudo-CT. MAE \pm SD ranged from $29.9 \pm 53.8 \mathrm{HU}$ to $37.6 \pm 82.6 \mathrm{HU}$ for the body and from $31.3 \pm 27.3 \mathrm{HU}$ to $37.3 \pm 35.8 \mathrm{HU}$ for the prostate.

\subsection{Hybrid approaches}

Other works use combinations of the above-described approaches to combine their strengths, reduce their weaknesses and palliate for limitations, approaches in this class are called hybrid $(77,78,79,44,80,81,46,82)$.

Hoffman et al. (78) combined atlas registration and pattern recognition to predict a pseudo-CT for attenuation correction. The approach consists of learning a model on a dataset of registered MR-CT atlases to define a mapping from MR intensities to CT intensities. The first step consists of using B-spline registration with mutual information as a similarity measure to construct the MR-CT atlas database. Then the MR atlases are registered to the test MR volume using spatial normalization and the same transformations are applied to the CT atlases. These transformed atlases are used to extract pairs of MR patches and their corresponding $\mathrm{CT}$ values at each voxel location. A regression process that incorporates prior knowledge from the transformed images and uses a kernel function to measure the degree of similarity between MR patches was used to predict CT values for an unseen MR patch and generate the final pseudo-CT. The approach overestimated the bone in case of the presence of a proximate lesion.

Chen et al. (79) estimated a pseudo-CT from standard T1-weighted MR sequences of the head taking into account distinction between bone and air. To do this, authors generated air maps from CT scans and rigidly registered them to the corresponding MR images. This was done for all the atlas images of the training set, and then all air maps were warped to the patient MR image to locate air, once this is done. For each air voxel, an average CT value is assigned from atlas voxels of the same location. At tissue location, hidden Markov Random Field (hMRF) and sparse regression were used to predict CT values. The idea is to measure the resemblance between the MR atlas patches and the patient MR patch to assign a high weight if the resemblance is strong, assuming that similar MR patches correspond to similar CT patches. The final value of the pseudo-CT patch is calculated using the weighted average of the overlap CT atlas patches. Despite the good results in PET simulation; $1.60 \pm 0.51 \%$ for the Mean Absolute Relative Error (MARE) and 5.45 $\pm 1.36 \%$ for the Full Width Tenth Maximum (FWTM), the approach presented some misclassification results where some bone was classified as air. Furthermore; when compared with the averaged atlas method, if one would choose a compromise between workload and accuracy, the averaged atlas approach would be chosen since the presented results are acceptable $(1.70 \pm 0.57 \%$ for MARE and $6.3 \pm 1.29 \%$ for FWTM).

In (44), Andreasen et al presented a patch-based approach for predicting pseudo-CT from conventional MR sequences. Five brain images from MR and CT were aligned using mutual information as a similarity measure (the aligned images constitute the patch database). Each patch $P(x)$ in an $x$ MR location corresponds to a $T(x)$ value defining an $\mathrm{HU}$ value in the corresponding aligned CT scan. The pseudo-CT for the test patient is predicted using an intensity-based nearest neighbour search in the patch database. For each test patch, the goal is to find the minimized squared $L_{2}$-norm between the test patch and the database of patches. $K$ most similar CT patches are found and the final CT patch value is obtained by 
computing a similarity-weighted average. The structural similarity measure was used to discard the high dissimilar patches and reduce the search space. This approach depends on anatomical similarities, and the assignment of the average of the surrounding patches can cause problems when the surrounding tissues are different from the one being calculated.

Siversson et al. (80) used an automatic tissue classification approach using statistical decomposition algorithm with image registration to predict $\mathrm{CT}$ images for the pelvic region. A database of contoured MR-CT pairs is used to register the atlas MR images to the patient's MR image. Each pair registration yields a candidate organ segmentation and the final MR segmentation is calculated using a weighted voting method. Next, a non-linear warping procedure is applied to each of the atlas MR images in order to align the segmented structures to the newly segmented MR image. The resulting deformation fields are applied to their corresponding CTs and the final pseudo-CT is generated by fusing all the deformed CTs. Mean absorbed dose differences to the target was $0.0 \% \pm 0.2$ (1.s.d) and the MAE was $36 \pm 4.1$ (1.s.d) within the body contour.

$\mathrm{Wu}$ et al. (46) used local sparse correspondence combination to predict a pseudo-CT for the head. They assumed that MR and CT patches (each patch is a feature vector) are located on two non-linear manifolds. The approach consists of constructing initial MR and CT patch dictionaries by collecting patches within a local search window, next, the Knnalgorithm is applied to restrict the number of patches in the dictionaries. The MR dictionary is used to linearly represent the MR testing sample while ensuring the locality of the representation. The final CT patches are predicted by doing a weighted average of the corresponding CT patches.

Demol et al. (82) introduced an approach that uses deformable image registration combined with MR intensity information to generate a pseudo-CT from T1-weighted MR images of the brain. This approach aims at incorporating the MR intensity values into the generation of the pseudo-CT. The approach starts by registering an atlas MR image to its corresponding CT image via rigid registration with mutual information as a similarity measure. Then, the atlas MR image is nonrigidly registered to the MR image of the patient using the hybrid deformable image registration algorithm ANACONDA. The same deformations are applied to the CT atlas. Later, these two deformed atlas images were resampled to the same coordinate grid to apply voxel intensity computations. I.e., in the deformed MR image, a certain group of similar voxels was selected by doing a local search inside a $9 \times 9 \times 9$ box centred at each voxel with the selection threshold set to $10 \%$. The pseudo-CT value is calculated by averaging the $\mathrm{CT}$ values at the corresponding voxel location of the deformed CT. Comparison with the real CT resulted in an MAE of $150 \mathrm{HU}$. The main limitation of the approach is that the MR intensity search introduced incoherent CT numbers due to increasing the search area when no corresponding voxels are found inside the search box. Furthermore, noise near bone and air cavities was detected.

A recent work of Burgos et al. (81) used a database containing delineated T1, T2, CT images and a manually segmented image to create a pseudo-CT by combining atlas registration with segmentation in a single iterative framework. First, the atlas T1 and T2 images are registered to the target MR image to obtain an initial segmentation, and the transformations are applied to the atlas CT images to obtain an initial pseudo-CT. The initial segmentation and pseudo-CT are used alongside with the atlas database as inputs for the next iteration, and the process is repeated until satisfactory results are obtained. The number of iterations was set to 
four and the registration was based on two similarity measures, namely: the Structural Similarity Extended to Irregular Regions of Interest (ROI-SSIM) (83), and the Local Similarity Measure (LSIM). The DSC was calculated to evaluate segmentation results, and values ranged from 0.73 to 0.9 for prostate, bladder, rectum and femur heads. The $\mathrm{MAE} \pm \mathrm{SD}$ was $45.7 \pm 4.6 \mathrm{HU}$, and the average difference of $\mathrm{D}_{98}$ in the PTV was $-0.14 \%$.

\section{Discussion}

Tables 1, 2, 3 and 4 represent the classification of methods with the datasets, body regions, MR sequences and some numeric results of pseudo-CT images generated using several methods. From the tables, It is clear that most of the research focused primarily on the brain and secondly on the pelvis regions whereas poor work concentrated on the liver. The MAE ranged from $80 \mathrm{HU}$ to $137 \mathrm{HU}$ and from $36.4 \mathrm{HU}$ to $74 \mathrm{HU}$ for the brain and pelvis, respectively, which are within acceptable ranges.

The use of more specialized MR sequences does not seem to improve results remarkably except having the bone visualization feature as a bonus. In addition, we notice a recent increasing interest in the Dixon MR sequence since it has the advantage of producing multiple contrast images with a single acquisition. As well as the incorporation of segmentation techniques which is taking place to account for different tissues present in the body.

Despite the clinically acceptable performance results of these approaches. Each class of methods presents some drawbacks and limitations that should be taken into consideration and could extend the field of research in MRI-only RT. Approaches that are based on using segmentation algorithms suffer from segmentation errors, which can result in a misclassification of voxels. Moreover, the bone is often ignored because the standard MR sequences do not show any signal from the bone. Some research has investigated the use of other more specialized MR sequences that are capable of detecting signals from the bone using two Times of Echo (TE) after the radio frequency (RF) excitation. This type of sequence is called Ultra-short Echo Times sequences (UTE) $(85,49,27,86,87,88,89,90,33)$. It relies on measuring early relaxation signals from cortical bone structures. Another specialized MR sequence for detecting the bone signal is Zero-Echo Time imaging (ZTE) $(91,92)$. Delso et al. (91) showed that the bone segmentation using ZTE sequences performed better than the UTE-Based segmentation. However, these techniques are limited by their expensive implementation requirements and long acquisition time. Furthermore, whole body UTE imaging results in increased noises because of the short relaxation times of the cortical bone (93).

Other attempts to detect the bone combined Short-TE sequences with Dixon pulse sequences in a fuzzy C-means framework to determine tissue classes including cortical bone $(94,33,34)$. Techniques incorporating machine learning schemes to segment the bone seem very promising; Bredfeldt et al. (41) segmented the contours of the vertebra bone from fat images using a learning approach (43, 42) and Liu et al. (39) applied a bone shape model to detect the pelvic bone; in addition, Femur bone was detected using 3D connected component analysis. 
Medical Technologies Journal, Volume: 2, Issue: 1, January-March 2018, Pages:150-178.

Doi :https://doi.org/10.26415/2572-004X-vol2iss1p150-178

\begin{tabular}{|c|c|c|c|c|c|c|c|c|}
\hline & Method & Organ & $\begin{array}{l}\text { Data } \\
\text { sets }\end{array}$ & MRI sequences & \multicolumn{4}{|c|}{ Reported results } \\
\hline \multirow{2}{*}{\multicolumn{2}{|c|}{$\begin{array}{l}\text { Image } \\
\text { registration } \\
\text { with hidden } \\
\text { MRF and } \\
\text { sparse } \\
\text { regression } \\
(79)\end{array}$}} & \multirow[b]{2}{*}{ Brain } & \multirow[b]{2}{*}{$\begin{array}{l}10 \\
\text { patients }\end{array}$} & \multirow[b]{2}{*}{$\begin{array}{l}\text { Tl-weighted MR } \\
\text { sequence }\end{array}$} & \multicolumn{2}{|c|}{ MARE } & \multicolumn{2}{|c|}{ FWTM } \\
\hline & & & & & \multicolumn{2}{|c|}{$1.60=0.51 \%$} & \multicolumn{2}{|c|}{$5.45 \pm 1.36 \%$} \\
\hline \multirow{2}{*}{\multicolumn{2}{|c|}{$\begin{array}{l}\text { Segmentation } \\
\text { with image } \\
\text { registration } \\
(80)\end{array}$}} & \multirow{2}{*}{$\begin{array}{l}\text { Pelris } \\
\text { Brain }\end{array}$} & \multirow{2}{*}{$\begin{array}{l}10 \\
\text { prostate } \\
\text { patients }\end{array}$} & \multirow{2}{*}{$\begin{array}{l}\text { 3D T2-weighted } \\
\text { MRI sequence; }\end{array}$} & \multicolumn{4}{|c|}{$\mathrm{MAE} \pm \mathrm{SD}(\mathrm{HU})$} \\
\hline & & & & & \multicolumn{4}{|c|}{$36 \pm 4.1$} \\
\hline \multirow{3}{*}{\multicolumn{2}{|c|}{$\begin{array}{l}\text { Local sparse } \\
\text { corresponden } \\
\text { ce }(46)\end{array}$}} & \multirow{3}{*}{ Brain } & \multirow{3}{*}{$\begin{array}{l}13 \\
\text { patients }\end{array}$} & \multirow{3}{*}{$\begin{array}{l}\text { T1- and T2- } \\
\text { weighted MRI } \\
\text { sequences }\end{array}$} & \multicolumn{4}{|c|}{$\mathrm{MAE}=\mathrm{SD}(\mathrm{HU})$} \\
\hline & & & & & $\begin{array}{l}\text { Using Tl- } \\
\text { weighted }\end{array}$ & \multicolumn{2}{|c|}{$\begin{array}{l}\text { Using T2- } \\
\text { weighted }\end{array}$} & $\begin{array}{l}\text { Using T1- } \\
\text { and T2- } \\
\text { weighted }\end{array}$ \\
\hline & & & & & $\begin{array}{l}124.6 \\
\pm 14.2 \\
\end{array}$ & \multicolumn{2}{|c|}{$\begin{array}{c}123.9= \\
17.1\end{array}$} & $\begin{array}{c}113.8= \\
16.8\end{array}$ \\
\hline \multirow{2}{*}{ 뇡 } & \multirow{2}{*}{$\begin{array}{l}\text { Image } \\
\text { registration } \\
\text { with intensity } \\
\text { conversion } \\
\text { (82) }\end{array}$} & \multirow{2}{*}{ Brain } & \multirow{2}{*}{$\begin{array}{l}22 \\
\text { patients }\end{array}$} & \multirow{2}{*}{$\begin{array}{l}\text { 3D Tl-weighted } \\
\text { sequence with } \\
\text { injection of } \\
\text { gadolinium. }\end{array}$} & \multicolumn{4}{|c|}{ MAE } \\
\hline & & & & & \multicolumn{4}{|c|}{$150 \mathrm{HU}$} \\
\hline & \multirow{2}{*}{$\begin{array}{l}\text { Iterative joint } \\
\text { segmentation } \\
\text { and pseudo- } \\
\text { CT generation } \\
\text { (81) }\end{array}$} & \multirow[t]{2}{*}{ Pelvis } & \multirow{2}{*}{$\begin{array}{l}15 \\
\text { prostate } \\
\text { cancer } \\
\text { patients }\end{array}$} & \multirow{2}{*}{$\begin{array}{l}\text { T1-and T2-weighted } \\
\text { MRI sequences. }\end{array}$} & \multicolumn{2}{|c|}{$M A E \Rightarrow S D$} & \multicolumn{2}{|c|}{$\mathrm{D}_{\mathrm{x} \times \mathrm{s}}$ in PTV } \\
\hline & & & & & $45.7=4$ & & & $-0.14 \%$ \\
\hline \multirow{2}{*}{\multicolumn{2}{|c|}{$\begin{array}{l}\text { Patch-based } \\
\text { generation } \\
\text { (44) }\end{array}$}} & \multirow[t]{2}{*}{ Brain } & $\begin{array}{l}5 \\
\text { patients }\end{array}$ & $\begin{array}{l}\text { - Tl-weighted 3D } \\
\text { Fast Field Echo } \\
\text { (FFE); }\end{array}$ & $\begin{array}{l}\text { Voxel-wise } \\
\text { (MLEve }\end{array}$ & & $\begin{array}{r}\text { mea } \\
\text { en }\end{array}$ & $\begin{array}{l}\text { o voxel-wise } \\
\text { or (MEvox) }\end{array}$ \\
\hline & & & & $\begin{array}{l}\text { - Two dUTE } \\
\text { sequences. }\end{array}$ & $85=141$ & & & $=14 \mathrm{HU}$ \\
\hline & $\begin{array}{l}\text { Pattem } \\
\text { recognition } \\
\text { with atlas } \\
\text { registration }\end{array}$ & Brain & $\begin{array}{l}17 \\
\text { patients }\end{array}$ & $\begin{array}{l}\text { Tl-weighted Spin- } \\
\text { Echo (SE) sequence. }\end{array}$ & $\mathrm{R}^{2}$ Coeffi & & & $\begin{array}{l}\text { Emor of } \\
\text { PET } \\
\text { antification }\end{array}$ \\
\hline & (78) & & & & $0.968=0$. & & & $3.2 \%$ \\
\hline
\end{tabular}

Table 1. Intensity-based approaches for generating pseudo-CT from MRI data. 


\begin{tabular}{|c|c|c|c|c|c|c|c|c|}
\hline & Method & Organ & $\begin{array}{c}\text { Dataset } \\
5\end{array}$ & MRI sequences & \multicolumn{4}{|c|}{ Reported results } \\
\hline \multirow{3}{*}{\multicolumn{2}{|c|}{$\begin{array}{l}\text { Fuzzy c- } \\
\text { means } \\
\text { Clustering } \\
\text { (32) }\end{array}$}} & \multirow[b]{3}{*}{ Brain } & \multirow[b]{3}{*}{$\begin{array}{l}10 \\
\text { subjects }\end{array}$} & \multirow{3}{*}{$\begin{array}{l}\text { - 3D T1-weighted } \\
\text { and 3D T2- } \\
\text { weighted; } \\
\text { - In-phase and out- } \\
\text { phase images of } \\
\text { water and fat; } \\
\text { - Ulura short echo } \\
\text { times UTE } \\
\text { sequence; } \\
\text { 2D multi-plane time- } \\
\text { of-flight (TOF) } \\
\text { angiography. }\end{array}$} & \multicolumn{4}{|c|}{ Correlation with real $\mathrm{CT}$} \\
\hline & & & & & \multicolumn{2}{|c|}{$\mathbb{R}^{2}$} & \multicolumn{2}{|r|}{$\mathrm{R}^{2}$} \\
\hline & & & & & \multicolumn{2}{|c|}{0.99} & \multicolumn{2}{|r|}{0.99} \\
\hline \multirow{2}{*}{\multicolumn{2}{|c|}{$\begin{array}{l}\text { Short-TE } \\
\text { Dixon } \\
\text { with FCM } \\
\text { clustering } \\
\text { (38) }\end{array}$}} & \multirow[t]{2}{*}{ Brain } & \multirow{2}{*}{$\begin{array}{l}10 \\
\text { subjects }\end{array}$} & \multirow{2}{*}{$\begin{array}{l}\text { - 3D Dixon-VIBE } \\
\text { sequence; } \\
\text { - Anatomical T1- } \\
\text { Turbo Spin Echo } \\
\text { (TSE); } \\
\text { - T2-TSE sequences; } \\
\text { - Echo-planar- } \\
\text { diffusion weighted } \\
\text { sequence. }\end{array}$} & \multicolumn{4}{|c|}{$\mathrm{MAE}=\mathrm{SD}$ in PET quantification } \\
\hline & & & & & \multicolumn{4}{|c|}{$2.4 \%=3.86 \%$} \\
\hline \multirow{2}{*}{\multicolumn{2}{|c|}{$\begin{array}{l}\text { UTE-m } \\
\text { Dixon } \\
\text { Clustering } \\
(30) \\
\end{array}$}} & \multirow[b]{2}{*}{ Brain } & \multirow[b]{2}{*}{$\begin{array}{l}9 \\
\text { patients }\end{array}$} & \multirow{2}{*}{$\begin{array}{l}\text { Undersampled single } \\
\text { acquisition UTE-m } \\
\text { Dixon sequence. }\end{array}$} & \multicolumn{2}{|c|}{$\mathrm{ME}=\mathrm{SD}$} & \multicolumn{2}{|c|}{$\mathrm{MAE}=\mathrm{SD}$} \\
\hline & & & & & \multicolumn{2}{|c|}{$-22 \pm 29 \mathrm{HU}$} & \multicolumn{2}{|c|}{$130 \pm 16 \mathrm{HU}$} \\
\hline & \multirow{3}{*}{$\begin{array}{l}\text { Short-TE } \\
\text { Dixon } \\
\text { with FCM } \\
\text { clustering } \\
\text { (33) }\end{array}$} & \multirow{3}{*}{ Brain } & \multirow{3}{*}{$\begin{array}{l}2 \\
\text { subjects }\end{array}$} & \multirow{3}{*}{$\begin{array}{l}\text { ShTE Dixon MRI } \\
\text { sequence. }\end{array}$} & \multicolumn{4}{|c|}{$\begin{array}{l}\text { Quantitative assessment parameters } \\
\text { for bone segmentation (mean=SD) }\end{array}$} \\
\hline & & & & & \multirow{2}{*}{$\begin{array}{c}\text { Accuracy } \\
0.977 \pm 0.0 \\
1 \\
\end{array}$} & \multicolumn{2}{|c|}{ Sensitivity } & Specificity \\
\hline & & & & & & 0.94 & $=0.0$ & $\begin{array}{c}0.987=0.0 \\
1\end{array}$ \\
\hline & $\begin{array}{l}\text { Classificat } \\
\text { ion with }\end{array}$ & & & $\begin{array}{l}\text { 3D gradient echo } \\
\text { sequence VIBE Dixon }\end{array}$ & & MAE & $A S D$ & \\
\hline & bone & Pelvis. & female & (Ti-weighted (in- & Solid & pone & & Inscle \\
\hline & $\begin{array}{l}\text { shape } \\
\text { model (39) }\end{array}$ & & & $\begin{array}{l}\text { phase) image, fat and } \\
\text { water images). }\end{array}$ & $274.9 \pm 2$ & $5.9 \mathrm{HU}$ & $13.7=$ & $=1.8 \mathrm{HU}$ \\
\hline & FCM & Liver & 16 & 3D gradient dual echo & & M & & \\
\hline & (41) & & subjects & sequence. & & 0 to 1 & $0 \mathrm{HU}$ & \\
\hline & $\begin{array}{l}\text { 4-class } \\
\text { tissue } \\
\text { segmentati }\end{array}$ & Brain & $\begin{array}{l}7 \\
\text { subjects }\end{array}$ & $\begin{array}{l}\text { - UTE Triple Echo } \\
\text { sequence (UTILE); } \\
\text {-2D mDixon } \\
\text { reconstructed water }\end{array}$ & $\begin{array}{c}\mathrm{R}^{2} \\
\text { Berween } \\
\text { Correctio } \\
\text { Maps }\end{array}$ & $\begin{array}{r}\text { B } \\
\text { Betr } \\
\text { PI } \\
\text { ims }\end{array}$ & & $\begin{array}{l}\text { Classificat } \\
\text { ion } \\
\text { accuracy }\end{array}$ \\
\hline & & & & and fat images). & 0.9920 & 0.9 & & $81.1 \%$ \\
\hline & $\begin{array}{l}\text { Auto- } \\
\text { segmentati }\end{array}$ & & $\begin{array}{l}4 \\
\text { glioblas }\end{array}$ & $\begin{array}{l}\text { - 3D T1 Turbo Field } \\
\text { Echo (TFE) }\end{array}$ & Percen & $\begin{array}{l}\text { it differen } \\
\text { paran }\end{array}$ & $\begin{array}{l}\text { ef of dos } \\
\text { eters }\end{array}$ & simetric \\
\hline & $\begin{array}{l}\text { on with } \\
\text { distortion } \\
\text { correction } \\
\text { (84) }\end{array}$ & Brain & $\begin{array}{l}\text { toma } \\
\text { multifor } \\
\text { m } \\
\text { patients }\end{array}$ & $\begin{array}{l}\text { sequence; } \\
\text {-3D T2 Turbo Spin } \\
\text { Echo (TSE) } \\
\text { sequence. (For } \\
\text { visualization). }\end{array}$ & $\begin{array}{l}0.9<D i \\
50<1.0\end{array}$ & $\begin{array}{c}0.1<D \\
\text { mean }< \\
0.3\end{array}$ & $\begin{array}{c}0.0<D \\
\min =0 \\
8\end{array}$ & $\begin{array}{c}0.2<D \\
\max <0 \\
.6\end{array}$ \\
\hline & $\begin{array}{l}\text { FCM } \\
\text { Segmentat }\end{array}$ & Brain & 10 & 3D Tl-weighted & $\begin{array}{r}\text { Mean A } \\
\text { Differ }\end{array}$ & $\begin{array}{l}\text { ssolute } \\
\text { ence }\end{array}$ & Correl & lation $\left(R^{2}\right)$ \\
\hline & ion (31) & & & & 2.4 & & & 0.91 \\
\hline & Tissue & & & - 2D Turbo Spin Echo & & MAE & range & \\
\hline & $\begin{array}{l}\text { classuticat } \\
\text { on with } \\
\text { discrimina } \\
\text { nt analysis } \\
\text { (37) }\end{array}$ & $\begin{array}{l}\text { Phanto } \\
\mathrm{m}\end{array}$ & $\begin{array}{l}3 \\
\text { phanto } \\
\text { ms }\end{array}$ & $\begin{array}{l}\text { (TSE) sequence; } \\
\text { - 3D Ultrashort Bcho } \\
\text { Times (UTE) } \\
\text { sequence. }\end{array}$ & & 81 to & $5 \mathrm{HU}$ & \\
\hline
\end{tabular}

Table 2. Segmentation-based approaches for generating pseudo-CT from MRI data. 
Medical Technologies Journal, Volume: 2, Issue: 1, January-March 2018, Pages:150-178.

Doi :https://doi.org/10.26415/2572-004X-vol2iss1p150-178

\begin{tabular}{|c|c|c|c|c|c|c|c|c|c|c|}
\hline & Method & Organ & Datasets & MRI sequences & \multicolumn{6}{|c|}{ Reported results } \\
\hline & \multirow{3}{*}{$\begin{array}{l}\text { Atlas } \\
\text { fusion and } \\
\text { segmentatio } \\
\text { n (75) }\end{array}$} & \multirow{3}{*}{ Pelvis } & \multirow{3}{*}{$\begin{array}{l}12 \text { patients } \\
\text { with loco- } \\
\text { regionally } \\
\text { advanced } \\
\text { rectal } \\
\text { cancer }\end{array}$} & \multirow{3}{*}{$\begin{array}{l}\text { MRI Dixon } \\
\text { volumetric } \\
\text { interpolated T1- } \\
\text { weighted sequence. }\end{array}$} & \multicolumn{6}{|c|}{ Mean \pm SD (Absolute mean \pm SD $)$} \\
\hline & & & & & \multicolumn{2}{|c|}{ Fat } & \multicolumn{2}{|c|}{ Soft-tissue } & \multicolumn{2}{|c|}{ Bone } \\
\hline & & & & & \multicolumn{2}{|c|}{$\begin{array}{c}2.2 \pm 5.5 \\
(5.6 \pm 4.5)\end{array}$} & \multicolumn{2}{|c|}{$\begin{array}{l}-2.0 \pm 4.1 \\
(5.0 \pm 3.9) \\
\end{array}$} & \multicolumn{2}{|c|}{$\begin{array}{l}-1.5 \pm 5.0 \\
(4.1 \pm 2.2)\end{array}$} \\
\hline & \multirow{2}{*}{$\begin{array}{l}\text { Multi-atlas } \\
\text { information } \\
\text { propagation } \\
(70)\end{array}$} & \multirow{2}{*}{ Brain } & \multirow{2}{*}{$\begin{array}{l}12 \text { patients } \\
\text { (optimisati } \\
\text { on) } \\
41 \text { patients } \\
\text { (validation } \\
\text { ) }\end{array}$} & \multirow{2}{*}{$\begin{array}{l}\text { T1-weighted MR } \\
\text { sequence. }\end{array}$} & \multicolumn{3}{|c|}{ Average $\mathrm{MAE} \pm \mathrm{SD}$} & \multicolumn{3}{|c|}{ Average $\mathrm{ME} \pm \mathrm{SD}$} \\
\hline & & & & & \multicolumn{3}{|c|}{$121 \pm 17 \mathrm{HU}$} & \multicolumn{3}{|c|}{$-7.3 \pm 23 \mathrm{HU}$} \\
\hline & \multirow{3}{*}{$\begin{array}{l}\text { Electron } \\
\text { density } \\
\text { mapping } \\
\text { for MRI } \\
(69)\end{array}$} & \multirow{3}{*}{ Pelvis } & \multirow{3}{*}{$\begin{array}{l}37 \text { patients } \\
\text { with } \\
\text { prostate } \\
\text { cancer }\end{array}$} & \multirow{3}{*}{$\begin{array}{l}\text { - T2 fast spin echo } \\
\text { FSE sequence; } \\
\text { T2* gradient echo } \\
\text { sequence; } \\
\text { - Whole pelvic fast } \\
\text { spin echo FSE } \\
\text { sequence. }\end{array}$} & \multicolumn{6}{|c|}{ Mean \pm SD $(\mathrm{HU})$} \\
\hline & & & & & \multicolumn{2}{|c|}{ Rectum } & Bladder & \multicolumn{2}{|c|}{ Bone } & prostate \\
\hline & & & & & \multicolumn{2}{|c|}{$54 \pm 143$} & $9 \pm 6$ & $\begin{array}{l}34 \\
\pm 8 \\
\end{array}$ & \multicolumn{2}{|c|}{$42 \pm 25$} \\
\hline & $\begin{array}{l}\text { Unifying } \\
\text { probabilisti }\end{array}$ & Brain & $\begin{array}{l}9 \text { patient } \\
\text { with brain }\end{array}$ & $\begin{array}{l}\text { T1-weighted rapid } \\
\text { gradient echo }\end{array}$ & & MAE \pm & SD & & Accurac & \\
\hline & (17) & & tumour & sequence. & & $26 \pm 25$ & $\mathrm{HU}$ & & $86.6 \%$ & \\
\hline & & & & & & RMSD & $\pm \mathrm{SD}$ & & $\begin{array}{l}\text { orrelati } \\
\text { oefficie }\end{array}$ & \\
\hline క్ర & $\begin{array}{l}\text { Atlas } \\
\text { registration }\end{array}$ & Brain & $\begin{array}{l}26 \text { patient } \\
\text { with } \\
\text { paediatric }\end{array}$ & $\begin{array}{l}\text { T2-weighted Turbo } \\
\text { Spin-Echo (T2 TSE) } \\
\text { prior to the injection }\end{array}$ & $\begin{array}{l}\text { ME } \\
\text { AN6 }\end{array}$ & $\begin{array}{c}\text { ME } \\
\text { AN1 } \\
2\end{array}$ & $\begin{array}{c}\text { PRGP1 } \\
2\end{array}$ & $\begin{array}{c}\text { M } \\
\text { E } \\
\text { A } \\
\text { N6 }\end{array}$ & $\begin{array}{c}\text { ME } \\
\text { AN } \\
12\end{array}$ & $\begin{array}{c}\text { PR } \\
\text { GP1 } \\
2\end{array}$ \\
\hline 离 & $\begin{array}{l}\text { with fusion } \\
\text { (71) }\end{array}$ & & $\begin{array}{l}\text { brain } \\
\text { tumour }\end{array}$ & of contrast agent. & $\begin{array}{l}224 \\
\pm 36 \\
\mathrm{HU}\end{array}$ & $\begin{array}{l}219 \\
\pm 35 \\
\text { HU }\end{array}$ & $\begin{array}{c}207 \pm 33 \\
\mathrm{HU}\end{array}$ & $\begin{array}{c}0 . \\
78 \\
7 \pm \\
0 . \\
06\end{array}$ & $\begin{array}{l}0.79 \\
8 \pm 0 \\
059\end{array}$ & $\begin{array}{r}0.81 \\
9 \pm 0 \\
058\end{array}$ \\
\hline & $\begin{array}{l}\text { Template- } \\
\text { based (66) }\end{array}$ & Brain & 4 patients & $\begin{array}{l}\text { High-resolution 3D } \\
\text { T1 weighted } \\
\text { volumetric MR using } \\
\text { MP-RAGE } \\
\text { sequence. }\end{array}$ & & $\begin{array}{r}\text { veresti } \\
\text { ra }\end{array}$ & $\begin{array}{l}\text { mation of } \mathrm{t} \\
\text { dioactivity }\end{array}$ & $\begin{array}{l}\text { rec } \\
\text { p to }\end{array}$ & istructe & \\
\hline & Combined & & 17 brain & & & ean di & tance & & $\begin{array}{l}\text { Aean } \mathrm{H} \\
\text { fferenc }\end{array}$ & \\
\hline & $\begin{array}{l}\text { deformable } \\
\text { registration }\end{array}$ & Brain & $\begin{array}{l}\text { tumour } \\
\text { patients }\end{array}$ & I & $\begin{array}{l}\text { Extern } \\
\text { contou }\end{array}$ & & $\begin{array}{c}\text { Bony } \\
\text { anatomy }\end{array}$ & & $<2 \mathrm{HL}$ & \\
\hline & & & & & $1,26 \mathrm{~m}$ & & $2.15 \mathrm{~mm}$ & & & \\
\hline & $\begin{array}{l}\text { Segmentati } \\
\text { on and }\end{array}$ & & $\begin{array}{l}39 \text { patients } \\
\text { with }\end{array}$ & T2-weighted MR & & & Paired $\mathrm{t}$ & & & \\
\hline & $\begin{array}{l}\text { pseudo-CT } \\
\text { generation } \\
(68)\end{array}$ & Pelvis & $\begin{array}{l}\text { prostate } \\
\text { cancer }\end{array}$ & sequence & & & $>0.0$ & & & \\
\hline & $\begin{array}{l}\text { Maximum } \\
\text { probability }\end{array}$ & & & T1-weighted MR & & Vox & kel classific & tion e & & \\
\hline & $\begin{array}{l}\text { Multi-Atlas } \\
\text { (74) }\end{array}$ & Brain & 27 patients & sequence & & & $7.81 \% \pm 1$ & $00 \%$ & & \\
\hline & $\begin{array}{l}\text { Landmark } \\
\text { image }\end{array}$ & Phanto & Phantom & T2-weighted MR & & & $\mathrm{AAE} \pm \mathrm{SD}(\mathrm{p}$ & ostate & & \\
\hline & $\begin{array}{l}\text { registration } \\
(76)\end{array}$ & & & sequence & & $31.3 \pm 2$ & $7.3 \mathrm{HU}$ to & $7.3 \pm 3$ & $.8 \mathrm{HU}$ & \\
\hline & Atlas-based & & & $\begin{array}{l}\text { T1-weighted 3D } \\
\text { spoiled gradient }\end{array}$ & & & MAE \pm & & & \\
\hline & $\begin{array}{l}\text { regression } \\
(72)\end{array}$ & Brain & 10 patients & $\begin{array}{l}\text { recalled echo } \\
\text { sequence }\end{array}$ & & & $113.4 \pm 17$ & $\mathrm{HU}$ & & \\
\hline
\end{tabular}

Table 3. Atlas-based approaches for generating pseudo-CT from MRI data. 


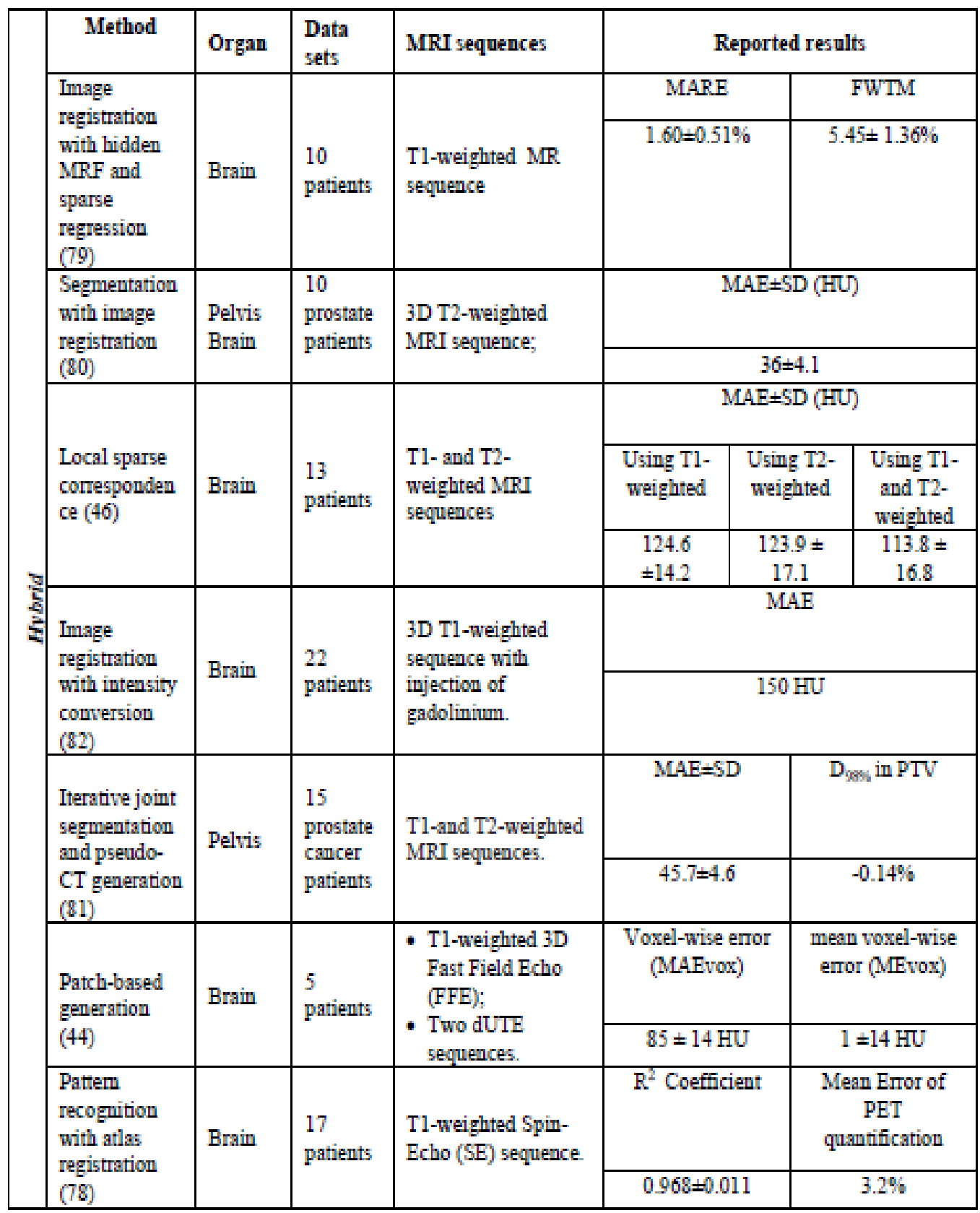

Table 4.Hybrid approaches for generating pseudo-CT from MRI data.

Intensity-based approaches assume a direct link between MR voxel values and CT values. However, this link cannot be characterised (78). This is because tissues like air and bone have different $\mathrm{CT}$ values whereas they present no signal on MR images. Moreover, the use of machine learning technique could be advantageous. Nevertheless, sufficient knowledge must be incorporated to improve the prediction quality, but the training time relatively increases with respect to the increased size of required training data sets. Edmund et al. (45) investigated the geometric and dosimetric performance of three intensity-based approaches using UTE MR sequences, namely: threshold-based segmentation, Bayesian segmentation, and statistical regression. In the threshold-based approach, thresholds are set manually to define tissues based on inspection of MR intensities. Voxel values are assigned according to echo times TE1 and TE2 intensities, and four classes of tissues were defined. The second approach is based on the Expectation Maximization(EM) algorithm, which estimates a probability that each voxel belongs to a specific tissue class, and then voxels are 
assigned to the class with the highest posterior probability. The regression-based approach uses both MR and CT data to train a regression model based on the EM algorithm that predicts a pseudo-CT for an untrained MR image. The investigation was performed on five patients; results show that the regression-based approach gave the best results in terms of geometric and dosimetric performances. Whereas, the other two approaches did not show a good correlation between geometrical agreement.

Approaches that rely on deformable image registration algorithms make the success of pseudo-CT generation related to the accuracy of registration; moreover, image registration introduces geometric uncertainties due to inter-patient variations and abnormalities. To assess the quality of deformable registration, Schreibmann et al. (67) developed a three-dimensional surface comparison tool that extracts a specific surface from the pseudo-CT and the simulated CT (gold standard) to compare the differences. Demol et al. (82) studied a specific case in detail with the aim of testing the performance of their proposed method (see subsection 3.4 for details of the approach) with atypical body structures. The case studied had a part of the skull bone removed surgically. The generated pseudo-CT presented additional bone in the location where the patient's MR image did not have any. Furthermore, the number of atlas images used to generate the pseudo-CT should be carefully selected (95) and the acquired atlas dataset should be representative of standard anatomy. The use of multi-atlas data fusion techniques $(74,17,71,70,75,96,69,72,97,98)$ appears to give improved results compared to the single atlas technique since the pseudo-CT values will be predicted from several CT atlas images. Mérida et al. (74) evaluated four multi-Atlas methods for pseudo-CT generation, their maximum probability approach (74) and three multi-Atlas approaches; the first method is a multi-Atlas propagation and fusion technique (70). The second is a best_10 approach where ten best-ranked deformed $\mathrm{CT}$ atlases are fused using non-weighted average and the last approach consists of fusing all deformed atlas CT images with a non-weighted average. Comparison results showed that the best_10 method performed better giving small voxel classification error $7.57 \pm 1.05$ compared to $7.95 \pm 1.00,7.81 \pm 1.00$ and $7.69 \pm 1.04$ for the Average, Max probability and the multi-Atlas propagation and fusion methods respectively.

Whelan et al. (99) evaluated the effect of electron density errors on dose calculation for the cervix cancer. They generated four pseudo-CT images using four methods: Atlas (100), homogenous bulk density assignment (16), rigid registration $(101,102)$ and bone bulk density (16). Comparison results show that the largest errors were observed for the bone density method when the bone is assigned the value of $1.21 \mathrm{~g} / \mathrm{cm}^{3}$ concluding that a wrong assignment of electron density values can result in dose changes when compared to the dose calculated on the gold standard CT.

One concern that should be considered is geometric distortions related to nonlinearity in spatial encoding gradients and chemical shift distortions caused by susceptibility effects. The quality of the generated pseudo-CT could be affected negatively if the used MR sequences contain distortions. Many research papers presented techniques to correct for geometric distortion (103) and chemical shift (104). In this scope, Stanescu et al. (84) investigated on the effect of distortion correction of MR images on dose calculation. The corrected MR images were autosegmented to define head structures (scalp, bone, and brain). Bulk CT values were assigned to these segmented regions. The dose calculations generated on these images ware compared to those generated by the conventional MRI-CT workflow. Percentual differences of the mean dose differences ranged from $0.2 \%$ to $0.3 \%$ for four patients. Beavis et al. (13) proved that it is possible to perform MRI-only RT 
by using a small field of view, an increased receiver bandwidth and a fast spin echo acquisition sequence.

The reported results for most of the above-mentioned research works are in acceptable ranges and confirm the success of pseudo-CT in replacing the original $\mathrm{CT}$ in RT. This field of research is emerging towards the use of MRI as the only modality in RT especially with the introduction of hybrid PET/MR systems for attenuation correction and it is opening research opportunities to improve the field of MRI-alone RT.

\section{Conclusion}

This paper aimed to review approaches for pseudo-CT generation from MR images for an MRI-only radiotherapy treatment workflow. We presented a classification of these approaches, discussed their strengths and weaknesses and covered some possible solutions and future orientations. Lately, research is oriented towards including specialised MRI sequences such as UTE and ZTE despite their complex implementation. Furthermore, new approaches and techniques are being integrated to deal with the bone visualisation issues. We notice that techniques that follow a segmentation scheme are being more established for the success brought by new segmentation algorithms that are implemented based on novel algorithms using deep learning or machine learning methods. We conclude that the quality of the generated pseudo-CT depends strongly on the applied approach and the used MR sequences. Although many approaches seem promising, one cannot choose the best method compared to the others; this is because different MR sequences, parameters, datasets and test metrics are used to generate the pseudo-CT and assess its quality. Hence, a benchmark is needed to set in common performance metrics.

\section{Authors biography}

Ms. Wafa Boukellouzis currently a Ph.D. student in Computer Science University of Ferhat Abbas, Setif, Algeria. She obtained her Master's degree in 2015 from M'HamedBouguerra University, Boumerdes, Algeria. Currently, she is working in the field of intelligent systems engineering. Her main research interests include medical image processing and machine learning.

Pr. Abdelouahab Moussaoui is a professor at the department of informatics, University of Ferhat Abbas, Setif, Algeria. His research interests are in the areas of data mining and machine learning (knowledge discovery, clustering, classification, etc.), signal and medical imaging (RMN, FMRN, PET, Mammography, ECG, EEG, etc.), bioinformatics and bio-mining (Pattern search, alignment of sequences, structure prediction, etc.), soft-computing and bio-inspired algorithms (Neural networks, GA, PSO, Artificial Ants, etc.)

\section{Conflicts of interest}

This paper is a revised and an expanded version of a paper entitled 'Classification of methods for generating pseudo-CT images for MRI-alone RT' presented at the International Workshop on Medical Technologies 2017 co-located with ICHSMT 2017, Tlemcen, Algeria, 10-12 October 2017 (23). 


\section{References}

1. O'Neill, B., Salerno, G., Thomas, K., Tait, D. and Brown, G. (2009). MR vs CT imaging: low rectal cancer tumour delineation for three-dimensional conformal radiotherapy. The British Journal of Radiology, [online] 82(978), pp.509-513. Available at: http://dx.doi.org/10.1259/bjr/60198873. [Accessed 8 Jun. 2017].

2. Rasch, C., Barillot, I., Remeijer, P., Touw, A., van Herk, M. and Lebesque, J. (1999). Definition of the prostate in CT and MRI: a multi-observer study. International Journal of Radiation Oncology*Biology*Physics, [online] 43(1), pp.57-66. Available at: $\quad$ http://dx.doi.org/10.1016/s0360-3016(98)00351-4. [Accessed 8 Jun. 2017].

3. Moser, E., Stadlbauer, A., Windischberger, A., Quick, H H., Ladd, M E., (2009). Magnetic resonance imaging methodology. European Journal of Nuclear Medicine and Molecular Imaging. [online] 36(1):30. Available at: http://dx.doi.org/10.1007/s00259-008-0938-3.

4. Chao, M., Xie, Y. and Xing, L. (2008). Auto-propagation of contours for adaptive prostate radiation therapy. Physics in Medicine and Biology, [online] 53(17), pp.4533-4542. Available at: http://dx.doi.org/10.1088/0031-9155/53/17/005. [Accessed 8 Jun. 2017].

5. Thor, M., Petersen, J., Bentzen, L., Høyer, M. and Muren, L. (2011). Deformable image registration for contour propagation from CT to cone-beam CT scans in radiotherapy of prostate cancer. ActaOncologica, [online] 50(6), pp.918-925. Available at: http://dx.doi.org/10.3109/0284186x.2011.577806. [Accessed 8 Jun. 2017].

6. Thörnqvist, S., Petersen, J., Høyer, M., Bentzen, L. and Muren, L. (2010). Propagation of target and organ at risk contours in radiotherapy of prostate cancer using deformable image registration. ActaOncologica, [online] 49(7), pp.1023-1032. Available at: http://dx.doi.org/10.3109/0284186x.2010.503662. [Accessed 8 Jun. 2017].

7. Van der Put, R., Kerkhof, E., Raaymakers, B., Jürgenliemk-Schulz, I. and Lagendijk, J. (2009). Contour propagation in MRI-guided radiotherapy treatment of cervical cancer: the accuracy of rigid, non-rigid and semi-automatic registrations. Physics in Medicine and Biology, [online] 54(23), pp.7135-7150. Available at: http://dx.doi.org/10.1088/0031-9155/54/23/007. [Accessed 8 Jun. 2017].

8. Faggiano, E., Fiorino, C., Scalco, E., Broggi, S., Cattaneo, M., Maggiulli, E., Dell 'O ca, I., Di Muzio, N., Calandrino, R. and Rizzo, G. (2011). An automatic contour propagation method to follow parotid gland deformation during head-and-neck cancer tomotherapy. Physics in Medicine and Biology, [online] 56(3), pp.775-791. Available at: http://dx.doi.org/10.1088/0031-9155/56/3/015. [Accessed 8 Jun. 2017].

9. Commandeur, F., Simon, A., Mathieu, R., Nassef, M., Ospina, J., Rolland, Y., Haigron, P., De Crevoisier, R. and Acosta, O. (2016). MRI to CT prostate registration for improved targeting in cancer external beam radiotherapy. IEEE Journal of Biomedical and Health Informatics, [online] pp.1-1. Available at: http://dx.doi.org/10.1109/jbhi.2016.2581881. [Accessed 8 Jun. 2017].

10. Cattaneo, G., Reni, M., Rizzo, G., Castellone, P., Ceresoli, G., Cozzarini, C., Ferreri, A., Passoni, P. and Calandrino, R. (2005). Target delineation in post-operative radiotherapy of brain gliomas: Interobserver variability and impact of image registration of MR (pre-operative) images on treatment planning CT scans. Radiotherapy and Oncology, [online] 75(2), pp.217223. Available at: http://dx.doi.org/10.1016/j.radonc.2005.03.012. [Accessed 8 Jun. 2017].

11. Nyholm, T., Nyberg, M., Karlsson, M. and Karlsson, M. (2009). Systematization of spatial uncertainties for comparison between a MR and a CT-based radiotherapy workflow for prostate treatments. Radiation Oncology, [online] 4(1), p.54. Available at: http://dx.doi.org/10.1186/1748-717x-4-54. [Accessed 8 Jun. 2017].

12. Ulin, K., Urie, M. and Cherlow, J. (2010). Results of a Multi-Institutional Benchmark Test for Cranial CT/MR Image Registration. International Journal of Radiation Oncology*Biology*Physics, [online] 77(5), pp.1584-1589. Available at: http://dx.doi.org/10.1016/j.ijrobp.2009.10.017. [Accessed 8 Jun. 2017].

13. Beavis, A., Gibbs, P., Dealey, R. and Whitton, V. (1998). Radiotherapy treatment planning of brain tumours using MRI alone. The British Journal of Radiology, [online] 71(845), pp.544548. Available at: http://dx.doi.org/10.1259/bjr.71.845.9691900. [Accessed 8 Jun. 2017].

14. Lee, Y. (2003). Radiotherapy treatment planning of prostate cancer using magnetic resonance imaging alone. Radiotherapy and Oncology, [online] 66(2), pp.203-216. Available at: http://dx.doi.org/10.1016/s0167-8140(02)00440-1. [Accessed 8 Jun. 2017]. 
15. Jonsson, J., Karlsson, M., Karlsson, M. and Nyholm, T. (2010). Treatment planning using MRI data: an analysis of the dose calculation accuracy for different treatment regions. Radiation Oncology, [online] 5(1), p.62. Available at: http://dx.doi.org/10.1186/1748-717x-5-62. [Accessed 8 Jun. 2017].

16. Lambert, J., Greer, P., Menk, F., Patterson, J., Parker, J., Dahl, K., Gupta, S., Capp, A., Wratten, C., Tang, C., Kumar, M., Dowling, J., Hauville, S., Hughes, C., Fisher, K., Lau, P., Denham, J. and Salvado, O. (2011). MRI-guided prostate radiation therapy planning: Investigation of dosimetric accuracy of MRI-based dose planning. Radiotherapy and Oncology, [online] 98(3), pp.330-334. Available at: http://dx.doi.org/10.1016/j.radonc.2011.01.012. [Accessed 8 Jun. 2017].

17. Gudur, M., Hara, W., Le, Q., Wang, L., Xing, L. and Li, R. (2014). A unifying probabilistic Bayesian approach to derive electron density from MRI for radiation therapy treatment planning. Physics in Medicine and Biology, [online] 59(21), pp.6595-6606. Available at: http://dx.doi.org/10.1088/0031-9155/59/21/6595. [Accessed 8 Jun. 2017].

18. Chen, L., Price, R., Wang, L., Li, J., Qin, L., McNeeley, S., Ma, C., Freedman, G. and Pollack, A. (2004). MRI-based treatment planning for radiotherapy: Dosimetric verification for prostate IMRT. International Journal of Radiation Oncology*Biology*Physics, [online] 60(2), pp.636647. Available at: http://dx.doi.org/10.1016/j.ijrobp.2004.05.068. [Accessed 8 Jun. 2017].

19. Eilertsen, K., Nilsen Tor Arne Vestad, L., Geier, O. and Skretting, A. (2008). A simulation of MRI based dose calculations on the basis of radiotherapy planning CT images. ActaOncologica, [online] 47(7), pp.1294-1302. Available at: http://dx.doi.org/10.1080/02841860802256426. [Accessed 8 Jun. 2017].

20. Pasquier, D., Palos, G., Castelain, B., Lartigau, E. and Rousseau, J. (2004). MRI simulation for conformal radiation therapy of prostate cancer. International Journal of Radiation Oncology*Biology*Physics, [online] 60(1), pp.S636-S637. Available at: http://dx.doi.org/10.1016/j.ijrobp.2004.07.656. [Accessed 8 Jun. 2017].

21. Hoogcarspel, S., Van der Velden, J., Lagendijk, J., van Vulpen, M. and Raaymakers, B. (2014). The feasibility of utilizing pseudo CT-data for online MRI based treatment plan adaptation for a stereotactic radiotherapy treatment of spinal bone metastases. Physics in Medicine and Biology, [online] 59(23), pp.7383-7391. Available at: http://dx.doi.org/10.1088/00319155/59/23/7383. [Accessed 8 Jun. 2017].

22. Karotki, A., Mah, K., Meijer, G. and Meltsner, M. (2011). Comparison of bulk electron density and voxel-based electron density treatment planning. Journal of Applied Clinical Medical Physics, [online] 12(4), pp.97-104. Available at: http://dx.doi.org/10.1120/jacmp.v12i4.3522. [Accessed 8 Jun. 2017].

23. W. Boukellouz and A. Moussaoui, Classification of methods for generating pseudo-CT images for MRI-alone RT, Medical Technologies Journal, vol. 1, no. 3, pp.54-54. Sep. 2017. Available at: http://dx.doi.org/10.26415/2572-004X-vol1iss3p54-54. [Accessed 28 Feb. 2018].

24. Dice, L. (1945). Measures of the Amount of Ecologic Association Between Species. Ecology, [online] 26(3), pp.297-302. Available at: http://dx.doi.org/10.2307/1932409. [Accessed 9 Jun. 2017].

25. Low, D., Harms, W., Mutic, S. and Purdy, J. (1998). A technique for the quantitative evaluation of dose distributions. Medical Physics, [online] 25(5), pp.656-661. Available at: http://dx.doi.org/10.1118/1.598248. [Accessed 9 Jun. 2017].

26. Edmund, J. and Nyholm, T. (2017). A review of substitute CT generation for MRI-only radiation therapy. Radiation Oncology, [online] 12(1). Available at: http://dx.doi.org/10.1186/s13014-016-0747-y. [Accessed 8 Jun. 2017].

27. Berker, Y., Franke, J., Salomon, A., Palmowski, M., Donker, H., Temur, Y., Mottaghy, F., Kuhl, C., Izquierdo-Garcia, D., Fayad, Z., Kiessling, F. and Schulz, V. (2012). MRI-Based Attenuation Correction for Hybrid PET/MRI Systems: A 4-Class Tissue Segmentation Technique Using a Combined Ultrashort-Echo-Time/Dixon MRI Sequence. Journal of Nuclear Medicine, [online] 53(5), pp.796-804. Available at: http://dx.doi.org/10.2967/jnumed.111.092577. [Accessed 8 Jun. 2017].

28. Dixon, W. (1984). Simple proton spectroscopic imaging. Radiology, [online] 153(1), pp.189194. Available at: http://dx.doi.org/10.1148/radiology.153.1.6089263. [Accessed 8 Jun. 2017].

29. Glover, G. and Schneider, E. (1991). Three-point dixon technique for true water/fat decomposition with B0 inhomogeneity correction. Magnetic Resonance in Medicine, [online] 18(2), pp.371-383. Available at: http://dx.doi.org/10.1002/mrm.1910180211. [Accessed 8 Jun. 2017]. 
30. Su, K., Hu, L., Stehning, C., Helle, M., Qian, P., Thompson, C., Pereira, G., Jordan, D., Herrmann, K., Traughber, M., Muzic, R. and Traughber, B. (2015). Generation of brain pseudoCTs using an undersampled, single-acquisition UTE-mDixon pulse sequence and unsupervised clustering. Medical Physics, [online] 42(8), pp.4974-4986. Available at: http://dx.doi.org/10.1118/1.4926756. [Accessed 8 Jun. 2017].

31. Zaidi, H., Montandon, M. and Slosman, D. (2003). Magnetic resonance imaging-guided attenuation and scatter corrections in three-dimensional brain positron emission tomography. Medical Physics, [online] 30(5), pp.937-948. Available at: http://dx.doi.org/10.1118/1.1569270. [Accessed 8 Jun. 2017].

32. Hsu, S., Cao, Y., Huang, K., Feng, M. and Balter, J. (2013). Investigation of a method for generating synthetic CT models from MRI scans of the head and neck for radiation therapy. Physics in Medicine and Biology, [online] 58(23), pp.8419-8435. Available at: http://dx.doi.org/10.1088/0031-9155/58/23/8419. [Accessed 8 Jun. 2017].

33. Khateri, P., Rad, H., Jafari, A. and Ay, M. (2014). A novel segmentation approach for implementation of MRAC in head PET/MRI employing Short-TE MRI and 2-point Dixon method in a fuzzy C-means framework. Nuclear Instruments and Methods in Physics Research Section A: Accelerators, Spectrometers, Detectors and Associated Equipment, [online] 734, pp.171-174. Available at: http://dx.doi.org/10.1016/j.nima.2013.09.006. [Accessed 8 Jun. 2017].

34. Khateri, P., Saligheh Rad, H., Jafari, A., FathiKazerooni, A., Akbarzadeh, A., ShojaeMoghadam, M., Aryan, A., Ghafarian, P. and Ay, M. (2015). Generation of a Four-Class Attenuation Map for MRI-Based Attenuation Correction of PET Data in the Head Area Using a Novel Combination of STE/Dixon-MRI and FCM Clustering. Molecular Imaging and Biology, [online] 17(6), pp.884-892. Available at: http://dx.doi.org/10.1007/s11307-015-08491. [Accessed 8 Jun. 2017].

35. Boettger, T., Nyholm, T., Karlsson, M., Nunna, C. and Celi, J. (2008). Radiation therapy planning and simulation with magnetic resonance images. Medical imaging, [online] Vol. 6918 (69181C-1). Available at: http://dx.doi.org/10.1117/12.770016.

36. Rahmer, J., Blume, U. and Börnert, P. (2007). Selective 3D ultrashort TE imaging: comparison of "dual-echo" acquisition and magnetization preparation for improving short-T2 contrast. Magnetic Resonance Materials in Physics, Biology and Medicine, [online] 20(2), pp.83-92. Available at: http://dx.doi.org/10.1007/s10334-007-0070-6. [Accessed 8 Jun. 2017].

37. Rank, C., Tremmel, C., Hünemohr, N., Nagel, A., Jäkel, O. and Greilich, S. (2013). MRI-based treatment plan simulation and adaptation for ion radiotherapy using a classification-based approach. Radiation Oncology, [online] 8(1), p.51. Available at: http://dx.doi.org/10.1186/1748-717x-8-51. [Accessed 8 Jun. 2017].

38. Navalpakkam, B., Braun, H., Kuwert, T. and Quick, H. (2013). Magnetic Resonance Based Attenuation Correction for PET/MR Hybrid Imaging Using Continuous Valued Attenuation Maps. Investigative Radiology, [online] 48(5), pp.323-332. Available at: http://dx.doi.org/10.1097/rli.0b013e318283292f. [Accessed 8 Jun. 2017].

39. Liu, L., Jolly, S., Cao, Y., Vineberg, K., Fessler, J. and Balter, J. (2017). Female pelvic synthetic CT generation based on joint intensity and shape analysis. Physics in Medicine and Biology, [online] 62(8), pp.2935-2949. Available at: http://dx.doi.org/10.1088/1361-6560/62/8/2935. [Accessed 8 Jun. 2017].

40. Liu, L., Cao, Y., Fessler, J., Jolly, S. and Balter, J. (2015). A female pelvic bone shape model for air/bone separation in support of synthetic CT generation for radiation therapy. Physics in Medicine and Biology, [online] 61(1), pp.169-182. Available at: http://dx.doi.org/10.1088/0031-9155/61/1/169. [Accessed 8 Jun. 2017].

41. Bredfeldt, J., Liu, L., Feng, M., Cao, Y. and Balter, J. (2017). Synthetic CT for MRI-based liver stereotactic body radiotherapy treatment planning. Physics in Medicine and Biology, [online] 62(8), pp.2922-2934. Available at: http://dx.doi.org/10.1088/1361-6560/aa5059. [Accessed 8 Jun. 2017].

42. Peng, Z., Zhong, J., Wee, W. and Lee, J. (2005). Automated vertebra detection and segmentation from the whole spine MR images. In: IEEE 27th annual international conference of the engineering in medicine and biology society, [online] pp.25272530, Available at: http://dx.doi.org/10.1109/IEMBS.2005.1616983.

43. Szu-Hao Huang, Yi-Hong Chu, Shang-Hong Lai and Novak, C. (2009). LearningBased Vertebra Detection and Iterative Normalized-Cut Segmentation for Spinal MRI. IEEE Transactions on Medical Imaging, [online] 28(10), pp.1595-1605. Available at: http://dx.doi.org/10.1109/tmi.2009.2023362. [Accessed 9 Jun. 2017]. 
44. Andreasen, D., Van Leemput, K., Hansen, R., Andersen, J. and Edmund, J. (2015). Patch-based generation of a pseudo CT from conventional MRI sequences for MRI-only radiotherapy of the brain. Medical Physics, [online] 42(4), pp.1596-1605. Available at: http://dx.doi.org/10.1118/1.4914158. [Accessed 8 Jun. 2017].

45. Edmund, J., Kjer, H., Van Leemput, K., Hansen, R., Andersen, J. and Andreasen, D. (2014). A voxel-based investigation for MRI-only radiotherapy of the brain using ultra short echo times. Physics in Medicine and Biology, [online] 59(23), pp.7501-7519. Available at: http://dx.doi.org/10.1088/0031-9155/59/23/7501. [Accessed 8 Jun. 2017].

46. Wu, Y., Yang, W., Lu, L., Lu, Z., Zhong, L., Huang, M., Feng, Y., Feng, Q. and Chen, W. (2016). Prediction of CT Substitutes from MR Images Based on Local Diffeomorphic Mapping for Brain PET Attenuation Correction. Journal of Nuclear Medicine, [online] 57(10), pp.16351641. Available at: http://dx.doi.org/10.2967/jnumed.115.163121. [Accessed 8 Jun. 2017].

47. Roy, S., Carras, A., Jog, A., Prince, L. and Lee, J. (2014). MR to CT registration of brains using image synthesis. In SPIE Medical Imaging, [online] 9034. Available at: http://dx.doi.org/10.1117/12.2043954.

48. Roy, S., Wang, W., Carass, A., Prince, J., Butman, J. and Pham, D. (2014). PET Attenuation Correction Using Synthetic CT from Ultrashort Echo-Time MR Imaging. Journal of Nuclear Medicine, [online] 55(12), pp.2071-2077. Available at: http://dx.doi.org/10.2967/jnumed.114.143958. [Accessed 8 Jun. 2017].

49. Johansson, A., Karlsson, M. and Nyholm, T. (2011). CT substitute derived from MRI sequences with ultrashort echo time. Medical Physics, [online] 38(5), pp.2708-2714. Available at: http://dx.doi.org/10.1118/1.3578928. [Accessed 8 Jun. 2017].

50. Johansson, A., Karlsson, M., Yu, J., Asklund, T. and Nyholm, T. (2012). Voxel-wise uncertainty in CT substitute derived from MRI. Medical Physics, [online] 39(6Part1), pp.32833290. Available at: http://dx.doi.org/10.1118/1.4711807. [Accessed 8 Jun. 2017].

51. Johansson, A., Garpebring, A., Karlsson, M., Asklund, T. and Nyholm, T. (2013). Improved quality of computed tomography substitute derived from magnetic resonance (MR) data by incorporation of spatial information--potential application for MR-only radiotherapy and attenuation correction in positron emission tomography. ActaOncologica, [online] 52(7), pp.1369-1373. Available at: http://dx.doi.org/10.3109/0284186x.2013.819119. [Accessed 8 Jun. 2017].

52. Kapanen, M. and Tenhunen, M. (2012). T1/T2*-weighted MRI provides clinically relevant pseudo-CT density data for the pelvic bones in MRI-only based radiotherapy treatment planning. ActaOncologica, [online] 52(3), pp.612-618. Available at: http://dx.doi.org/10.3109/0284186x.2012.692883. [Accessed 8 Jun. 2017].

53. Kim, J., Glide-Hurst, C., Doemer, A., Wen, N., Movsas, B. and Chetty, I. (2015). Implementation of a Novel Algorithm For Generating Synthetic CT Images From Magnetic Resonance Imaging Data Sets for Prostate Cancer Radiation Therapy. International Journal of Radiation Oncology*Biology*Physics, [online] 91(1), pp.39-47. Available at: http://dx.doi.org/10.1016/j.ijrobp.2014.09.015. [Accessed 8 Jun. 2017].

54. Korhonen, J., Kapanen, M., Keyriläinen, J., Seppälä, T. and Tenhunen, M. (2013). A dual model HU conversion from MRI intensity values within and outside of bone segment for MRI-based radiotherapy treatment planning of prostate cancer. Medical Physics, [online] 41(1), p.011704. Available at: http://dx.doi.org/10.1118/1.4842575. [Accessed 8 Jun. 2017].

55. Zhong, L., Lin, L., Lu, Z., Wu, Y., Lu, Z., Huang, M., Yang, W. and Feng, Q. (2016). Predict CT image from MRI data using KNN-regression with learned local descriptors. In: IEEE 13th international symposium on Biomedical imaging, [online] pp.743-746, Available at: http://dx.doi.org/10.1109/ISBI.2016.7493373.

56. Zhen, X., Wang, Z., Yu, M. and Li, S. (2015). Supervised descriptor learning for multi-output regression. In: EEE Conference on computer vision and pattern recognition, [online] pp.1211-1218, Available at: http://dx.doi.org/10.1109/CVPR.2015.7298725.

57. Huynh, T., Gao, Y., Kang, J., Wang, L., Zhang, P., Lian, J. and Shen, D. (2016). Estimating CT Image From MRI Data Using Structured Random Forest and Auto-Context Model. IEEE Transactions on Medical Imaging, [online] 35(1), pp.174-183. Available at: http://dx.doi.org/10.1109/tmi.2015.2461533. [Accessed 8 Jun. 2017].

58. Brown, L. (1992). A survey of image registration techniques. ACM Computing Surveys, [online] 24(4), pp.325-376. Available at: http://dx.doi.org/10.1145/146370.146374. [Accessed 8 Jun. 2017]. 
59. Rueckert, D and Schnabel. J. A. (2010) Medical image registration.Biomedical Image Processing, Springer, [online] pp. 131-154. Available at: http://dx.doi.org/10.1016/10.1007/978-3-642-15816-2_5.

60. Zitová, B. and Flusser, J. (2003). Image registration methods: a survey. Image and Vision Computing, [online] 21(11), pp.977-1000. Available at: http://dx.doi.org/10.1016/s02628856(03)00137-9. [Accessed 8 Jun. 2017].

61. Maintz, J. and Viergever, M. (1998). A survey of medical image registration. Medical Image Analysis, [online] 2(1), pp.1-36. Available at: http://dx.doi.org/10.1016/s1361-8415(01)800268. [Accessed 8 Jun. 2017].

62. Modersitzki, J. (2004). Numerical methods for image registration. Oxford :Oxford Univ Press on demand.

63. Hajnal, J., Hill, D.L.G. and Hawkes, D.J (2001). Medical image registration. CRC Press.

64. Devic, S. (2012). MRI simulation for radiotherapy treatment planning. Medical Physics, [online] 39(11), pp.6701-6711. Available at: http://dx.doi.org/10.1118/1.4758068. [Accessed 8 Jun. 2017].

65. Lester, H. and Arridge, S. (1999). A survey of hierarchical non-linear medical image registration. Pattern Recognition, [online] 32(1), pp.129-149. Available at: http://dx.doi.org/10.1016/s0031-3203(98)00095-8. [Accessed 8 Jun. 2017].

66. Kops, E. and Hersog, H. (2007). Alternative methods for attenuation correction for PET images in MR-PET scanners. In: IEEE Nuclear science symposium conference record, [online] 6, pp.4327-4330. Available at: http://dx.doi.org/10.1109/NSSMIC.2007.4437073. [Accessed 8 Jun. 2017].

67. Schreibmann, E., Nye, J., Schuster, D., Martin, D., Votaw, J. and Fox, T. (2010). MR-based attenuation correction for hybrid PET-MR brain imaging systems using deformable image registration. Medical Physics, [online] 37(5), pp.2101-2109. Available at: http://dx.doi.org/10.1118/1.3377774. [Accessed 8 Jun. 2017].

68. Greer, P., Dowling, J., Lambert, J., Frippe, J., Parker, J., Denham, J., Wratten, C., Capp, A. and Salvado, O. (2011). A magnetic resonance imaging-based workflow for planning radiation therapy for prostate cancer. Medical journal of Australia, [online] 194(4), pp.S24-S27. PMID: 21401484.

69. Dowling, J., Lambert, J., Parker, J., Salvado, O., Fripp, J., Capp, A., Wratten, C., Denham, J. and Greer, P. (2012). An Atlas-Based Electron Density Mapping Method for Magnetic Resonance Imaging (MRI)-Alone Treatment Planning and Adaptive MRI-Based Prostate Radiation Therapy. International Journal of Radiation Oncology*Biology*Physics, [online] 83(1), pp.e5-e11. Available at: http://dx.doi.org/10.1016/j.ijrobp.2011.11.056. [Accessed 8 Jun. 2017].

70. Burgos, N., Cardoso, M., Thielemans, K., Duncan, J., Atkinson, D., Arridge, S., Hutton, B. and Ourselin, S. (2014). Attenuation correction synthesis for hybrid PET-MR scanners: validation for brain study applications. EJNMMI Physics, [online] 1(1), p.A52. Available at: http://dx.doi.org/10.1186/2197-7364-1-s1-a52. [Accessed 8 Jun. 2017].

71. Uh, J., Merchant, T., Li, Y., Li, X. and Hua, C. (2014). MRI-based treatment planning with pseudo CT generated through atlas registration. Medical Physics, [online] 41(5), p.051711. Available at: http://dx.doi.org/10.1118/1.4873315. [Accessed 8 Jun. 2017].

72. Sjölund, J., Forsberg, D., Andersson, M. and Knutsson, H. (2015). Generating patient specific pseudo-CT of the head from MR using atlas-based regression. Physics in Medicine and Biology, [online] 60(2), pp.825-839. Available at: http://dx.doi.org/10.1088/0031-9155/60/2/825. [Accessed 8 Jun. 2017].

73. Knutsson, H. and Andersson, M. (2005). Morphons: segmentation using elastic canvas and paint on priors. In: IEEE International conference on image processing, [online] 2, pp.II-1226. Available at: http://dx.doi.org/10.1009/ICIP.2005.1530283. [Accessed 8 Jun. 2017].

74. Mérida, I., Costes, N., Heckemann, R. and Hammers, A. (2015). Pseudo-CT generation in brain MR-PET attenuation correction: comparison of several multi-atlas methods. EJNMMI Physics, [online] 2(1), p.A29. Available at: http://dx.doi.org/10.1186/2197-7364-2-s1-a29. [Accessed 8 Jun. 2017].

75. Arabi, H., Koutsouvelis, N., Rouzaud, M., Miralbell, R. and Zaidi, H. (2016). Atlas-guided generation of pseudo-CT images for MRI-only and hybrid PET/MRI-guided radiotherapy treatment planning. Physics in Medicine and Biology, [online] 61(17), pp.6531-6552. Available at: http://dx.doi.org/10.1088/0031-9155/61/17/6531. [Accessed 8 Jun. 2017]. 
76. Kraus, K., Jäkel, O., Niebuhr, N. and Pfaffenberger, A. (2017). Generation of synthetic CT data using patient specific daily MR image data and image registration. Physics in Medicine and Biology, [online] 62(4), pp.1358-1377. Available at: http://dx.doi.org/10.1088/13616560/aa5200. [Accessed 8 Jun. 2017].

77. Izquierdo-Garcia, D., Hansen, A., Forster, S., Benoit, D., Schachoff, S., Furst, S., Chen, K., Chonde, D. and Catana, C. (2014). An SPM8-Based Approach for Attenuation Correction Combining Segmentation and Nonrigid Template Formation: Application to Simultaneous PET/MR Brain Imaging. Journal of Nuclear Medicine, [online] 55(11), pp.1825-1830. Available at: http://dx.doi.org/10.2967/jnumed.113.136341. [Accessed 8 Jun. 2017].

78. Hofmann, M., Steinke, F., Scheel, V., Charpiat, G., Farquhar, J., Aschoff, P., Brady, M., Scholkopf, B. and Pichler, B. (2008). MRI-Based Attenuation Correction for PET/MRI: A Novel Approach Combining Pattern Recognition and Atlas Registration. Journal of Nuclear Medicine, [online] 49(11), pp.1875-1883. Available at: http://dx.doi.org/10.2967/jnumed.107.049353. [Accessed 8 Jun. 2017].

79. Chen, Y., Juttukonda, M., Lee, Y., Su, Y., Espinoza, F., Lin, W., Shen, D., Lulash, D. and An, H. (2014). MRI based attenuation correction for PET/MRI via MRF segmentation and sparse regression estimated CT. In: IEEE 11th international symposium on Biomedical imaging, [online] 60(2), pp.1364-1367. Available at: http://dx.doi.org/10.1109/ISBI.2014.6868131. [Accessed 8 Jun. 2017].

80. Siversson, C., Nordström, F., Nilsson, T., Nyholm, T., Jonsson, J., Gunnlaugsson, A. and Olsson, L. (2015). Technical Note: MRI only prostate radiotherapy planning using the statistical decomposition algorithm. Medical Physics, [online] 42(10), pp.6090-6097. Available at: http://dx.doi.org/10.1118/1.4931417. [Accessed 8 Jun. 2017].

81. Burgos, N., Guerreiro, F., McClelland, J., Presles, B., Modat, M., Nill, S., Dearnaley, D., deSouza, N., Oelfke, U., Knopf, A., Ourselin, S. and Jorge Cardoso, M. (2017). Iterative framework for the joint segmentation and CT synthesis of MR images: application to MRI-only radiotherapy treatment planning. Physics in Medicine and Biology, [online] 62(11), pp.42374253. Available at: http://dx.doi.org/10.1088/1361-6560/aa66bf. [Accessed 8 Jun. 2017].

82. Demol, B., Boydev, C., Korhonen, J. and Reynaert, N. (2016). Dosimetric characterization of MRI-only treatment planning for brain tumors in atlas-based pseudo-CT images generated from standard T1-weighted MR images. Medical Physics, [online] 43(12), pp.6557-6568. Available at: http://dx.doi.org/10.1118/1.4967480. [Accessed 8 Jun. 2017].

83. Wang, Z., Bovik, A., Sheikh, H. and Simoncelli, E. (2004). Image Quality Assessment: From Error Visibility to Structural Similarity. IEEE Transactions on Image Processing, [online] 13(4), pp.600-612. Available at: http://dx.doi.org/10.1109/tip.2003.819861. [Accessed 8 Jun. 2017].

84. Stanescu, T., Jans, H., Pervez, N., Stavrev, P. and Fallone, B. (2008). A study on the magnetic resonance imaging (MRI)-based radiation treatment planning of intracranial lesions. Physics in Medicine and Biology, [online] 53(13), pp.3579-3593. Available at: http://dx.doi.org/10.1088/0031-9155/53/13/013. [Accessed 8 Jun. 2017].

85. Catana, C., van der Kouwe, A., Benner, T., Michel, C., Hamm, M., Fenchel, M., Fischl, B., Rosen, B., Schmand, M. and Sorensen, A. (2010). Toward Implementing an MRI-Based PET Attenuation-Correction Method for Neurologic Studies on the MR-PET Brain Prototype. Journal of Nuclear Medicine, [online] 51(9), pp.1431-1438. Available at: http://dx.doi.org/10.2967/jnumed.109.069112. [Accessed 8 Jun. 2017].

86. Keereman, V., Fierens, Y., Broux, T., De Deene, Y., Lonneux, M. and Vandenberghe, S. (2010). MRI-Based Attenuation Correction for PET/MRI Using Ultrashort Echo Time Sequences. Journal of Nuclear Medicine, [online] 51(5), pp.812-818. Available at: http://dx.doi.org/10.2967/jnumed.109.065425. [Accessed 8 Jun. 2017].

87. Aitken, A., Giese, D., Tsoumpas, C., Schleyer, P., Kozerke, S., Prieto, C. and Schaeffter, T. (2013). Improved UTE-based attenuation correction for cranial PET-MR using dynamic magnetic field monitoring. Medical Physics, [online] 41(1), p.012302. Available at: http://dx.doi.org/10.1118/1.4837315. [Accessed 8 Jun. 2017].

88. Buerger, C., Aitken, A., Tsoumpas, C., King, A., Schulz, V., Marsden, P. and Schaeffer, T. (2011). Investigation of 4D PET attenuation correction using ultra-short-echo time MR. In: Nuclear science symposium and medical imaging conference (NSS/MIC). IEEE, [online] 60(2), pp.3558-3561. Available at: http://dx.doi.org/10.1109/NSSMIC.2011.6153668. [Accessed 8 Jun. 2017].

89. Ghose, S., Dowling, J., Rai, R. and Liney, G. (2017). Substitute CT generation from a single ultra short time echo MRI sequence: preliminary study. Physics in Medicine and Biology, 
[online] 62(8), pp.2950-2960. Available at: http://dx.doi.org/10.1088/1361-6560/aa508a. [Accessed 8 Jun. 2017].

90. Juttukonda, M., Mersereau, B., Chen, Y., Su, Y., Rubin, B., Benzinger, T., Lalush, D. and An, H. (2015). MR-based attenuation correction for PET/MRI neurological studies with continuous-valued attenuation coefficients for bone through a conversion from R2* to CT-Hounsfield units. NeuroImage, [online] 112, pp.160168. Available at: http://dx.doi.org/10.1016/j.neuroimage.2015.03.009. [Accessed 8 Jun. 2017].

91. Delso, G., Wiesinger, F., Sacolick, L., Kaushik, S., Shanbhag, D., Hullner, M. and VeitHaibach, P. (2015). Clinical Evaluation of Zero-Echo-Time MR Imaging for the Segmentation of the Skull. Journal of Nuclear Medicine, [online] 56(3), pp.417-422. Available at: http://dx.doi.org/10.2967/jnumed.114.149997. [Accessed 8 Jun. 2017].

92. Wiesinger, F., Sacolick, L., Menini, A., Kaushik, S., Ahn, S., Veit-Haibach, P., Delso, G. and Shanbhag, D. (2015). Zero TEMR bone imaging in the head. Magnetic Resonance in Medicine, [online] 75(1), pp.107-114. Available at: http://dx.doi.org/10.1002/mrm.25545. [Accessed 8 Jun. 2017].

93. Kim, J., Lee, J., Song, I. and Lee, D. (2012). Comparison of Segmentation-Based Attenuation Correction Methods for PET/MRI: Evaluation of Bone and Liver Standardized Uptake Value with Oncologic PET/CT Data. Journal of Nuclear Medicine, [online] 53(12), pp.1878-1882. Available at: http://dx.doi.org/10.2967/jnumed.112.104109. [Accessed 8 Jun. 2017]

94. Reza Ay, M., Akbarzadeh, A., Ahmadian, A. and Zaidi, H. (2014). Classification of bones from MR images in torso PET-MR imaging using a statistical shape model. Nuclear Instruments and Methods in Physics Research Section A: Accelerators, Spectrometers, Detectors and Associated Equipment, [online] 734, pp.196-200. Available at: http://dx.doi.org/10.1016/j.nima.2013.09.007. [Accessed 8 Jun. 2017].

95. Aljabar, P., Heckemann, R., Hammers, A., Hajnal, J. and Rueckert, D. (2009). Multi-atlas based segmentation of brain images: Atlas selection and its effect on accuracy. NeuroImage, [online] 46(3), pp.726-738. Available at: http://dx.doi.org/10.1016/j.neuroimage.2009.02.018. [Accessed 8 Jun. 2017].

96. Artaechevarria, X., Munoz-Barrutia, A. and Ortiz-de-Solorzano, C. (2009). Combination Strategies in Multi-Atlas Image Segmentation: Application to Brain MR Data. IEEE Transactions on Medical Imaging, [online] 28(8), pp.1266-1277. Available at: http://dx.doi.org/10.1109/tmi.2009.2014372. [Accessed 8 Jun. 2017].

97. Mehranian, A., Arabi, H. and Zaidi, H. (2016). Quantitative analysis of MRI-guided attenuation correction techniques in time-of-flight brain PET/MRI. NeuroImage, [online] 130, pp.123-133. Available at: http://dx.doi.org/10.1016/j.neuroimage.2016.01.060. [Accessed 8 Jun. 2017].

98. Ren, S., Hara, W., Wang, L., Buyyounouski, M., Le, Q., Xing, L. and Li, R. (2017). Robust Estimation of Electron Density From Anatomic Magnetic Resonance Imaging of the Brain Using a Unifying Multi-Atlas Approach. International Journal of Radiation Oncology*Biology*Physics, [online] 97(4), pp.849-857. Available at: http://dx.doi.org/10.1016/j.ijrobp.2016.11.053. [Accessed 8 Jun. 2017].

99. Whelan, B., Kumar, S., Dowling, J., Begg, J., Lambert, J., Lim, K., Vinod, S., Greer, P. and Holloway, L. (2015). Utilising pseudo-CT data for dose calculation and plan optimization in adaptive radiotherapy. Australasian Physical \& Engineering Sciences in Medicine, [online] 38(4), pp.561-568. Available at: http://dx.doi.org/10.1007/s13246-015-0376-z. [Accessed 8 Jun. 2017].

100.Zerda, A., Armbruster, B. and Xing, L. (2007). Formulating adaptive radiation therapy (ART) treatment planning into a closed-loop control framework. Physics in Medicine and Biology, [online] 52(14), pp.4137-4153. Available at: http://dx.doi.org/10.1088/0031-9155/52/14/008. [Accessed 8 Jun. 2017].

101.Roberson, P., McLaughlin, P., Narayana, V., Troyer, S., Hixson, G. and Kessler, M. (2005). Use and uncertainties of mutual information for computed tomography/magnetic resonance (CT/MR) registration post permanent implant of the prostate. Medical Physics, [online] 32(2), pp.473-482. Available at: http://dx.doi.org/10.1118/1.1851920. [Accessed 8 Jun. 2017]

102. Yang, Y., Schreibmann, E., Li, T., Wang, C. and Xing, L. (2007). Evaluation of on-board kV cone beam CT (CBCT)-based dose calculation. Physics in Medicine and Biology, [online] 52(3), pp.685-705. Available at: http://dx.doi.org/10.1088/0031-9155/52/3/011. [Accessed 8 Jun. 2017]. 
Medical Technologies Journal, Volume: 2, Issue: 1, January-March 2018, Pages:150-178.

Doi :https://doi.org/10.26415/2572-004X-vol2iss1p150-178

103.Korsholm, M., Waring, L. and Edmund, J. (2014). A criterion for the reliable use of MRI-only radiotherapy. Radiation Oncology, [online] 9(1), p.16. Available at: http://dx.doi.org/10.1186/1748-717x-9-16. [Accessed 8 Jun. 2017].

104. Walker, A., Liney, G., Metcalfe, P. and Holloway, L. (2014). MRI distortion: considerations for MRI based radiotherapy treatment planning. Australian Physical \& Engineering Sciences in Medicine, [online] 37(1), pp.103-113. Available at: http://dx.doi.org/10.1007/s13246-0140252-2. [Accessed 8 Jun. 2017]. 